\title{
Wind effect on the Atlantic meridional overturning circulation via sea ice and vertical diffusion
}

\author{
Haijun Yang ${ }^{1}$ Kun Wang ${ }^{1} \cdot$ Haijin Dai $^{1} \cdot$ Yuxing Wang ${ }^{1} \cdot$ Qing Li $^{1}$
}

Received: 19 August 2014 / Accepted: 19 July 2015 / Published online: 4 August 2015

(C) The Author(s) 2015. This article is published with open access at Springerlink.com

\begin{abstract}
Effects of wind and fresh water on the Atlantic meridional overturning circulation (AMOC) are investigated using a fully coupled climate model. The AMOC can change significantly when perturbed by either wind stress or freshwater flux in the North Atlantic. This study focuses on wind stress effect. Our model results show that the wind forcing is crucial in maintaining the AMOC. Reducing wind forcing over the ocean can cause immediately weakening of the vertical salinity diffusion and convection in the mid-high latitudes Atlantic, resulting in an enhancement of vertical salinity stratification that restrains the deep water formation there, triggering a slowdown of the thermohaline circulation. As the thermohaline circulation weakens, the sea ice expands southward and melts, providing the upper ocean with fresh water that weakens the thermohaline circulation further. The wind perturbation experiments suggest a positive feedback between sea-ice and thermohaline circulation strength, which can eventually result in a complete shutdown of the AMOC. This study also suggests that sea-ice variability may be also important to the natural AMOC variability on decadal and longer timescales.
\end{abstract}

Keywords AMOC $\cdot$ Wind effect $\cdot$ Freshwater flux $\cdot$ Sea ice $\cdot$ Vertical diffusion $\cdot$ Positive feedback

Haijun Yang

hjyang@pku.edu.cn

1 Laboratory for Climate and Ocean-Atmosphere Studies (LaCOAS) and Department of Atmospheric and Oceanic Sciences, School of Physics, Peking University, 209 Chengfu Road, Beijing 100871, China

\section{Introduction}

What determines the Atlantic meridional overturning circulation (AMOC) is one of the classic questions that have weighted on oceanographers and climatologists for decades. The AMOC is one of the key elements of the global climate system. It plays a critical role in maintaining global ocean heat and freshwater balances. It is commonly recognized that the AMOC is sustained by the North Atlantic deep-water (NADW) formation (e.g., Delworth et al. 1993; Delworth and Mann 2000; Marshall et al. 2001; Latif et al. 2004; Jungclaus et al. 2005; Knight et al. 2005; Swingedouw et al. 2007) and by the Ekman pumping in the Southern Ocean (e.g., Toggweiler and Samuels 1995, 1998; Wunsch and Ferrari 2004; Kuhlbrodt et al. 2007). Surface wind forcing, freshwater flux, ocean tides, and convections are all critical in providing energy for the NADW formation (Wunsch 2000; Gregory and Tailleux 2011). The Ekman pumping in the Southern Ocean is forced by local surface winds. Therefore, changes in both NADW formation and Southern Ocean surface winds can cause changes in the AMOC. The former tends to control shorter-term variability, while the latter has a bigger effect on the mean state of the AMOC (Delworth and Zeng 2008).

Despite common views on AMOC's fundamentals, many questions remain. For example, do local or remote processes dominate the NADW formation, and thereby control the AMOC variability? The local processes include convection, surface buoyancy flux, turbulent mixing, and diffusion (e.g., Welander 1986; Marotzke 1997; Nilsson et al. 2003). The remote processes include the northward freshwater/heat advection from the lower latitude (Delworth et al. 1993; Delworth and Mann 2000; Bentsen et al. 2004; Latif et al. 2004; Jungclaus et al. 2005; Knight et al. 2005; Swingedouw et al. 2007), atmospherically-driven 
freshwater transport from the Arctic (Delworth et al. 1997; Holland et al. 2001; Jungclaus et al. 2005) as well as seaice change in the Greenland-Iceland-Norwegian (GIN) seas (Zhang and Vallis 2006; Dima and Lohmann 2007; Drinkwater et al. 2014). The roles of these processes have been studied extensively, however, what are the deterministic factors for the AMOC remain unanswered. Regardless of local or remote forcing, the key question is what processes dominate changes in buoyancy (particularly salinity) field in the NADW formation region. Since the ocean is driven by winds and surface buoyancy flux, the question can be alternatively described as follows: which forcing is more important for driving the AMOC and, which process plays the dominant role in the AMOC change under different forcings?

A change in local salinity can occur through meridional advection, local wind and buoyancy flux. Usually, the interplay between local and remote processes results in AMOC change. Different processes, however, may play different roles at different stages of AMOC change. For example, hosing fresh water into the North Atlantic can shut down the AMOC (Stocker and Wright 1991; Manabe and Stouffer 1999; Stouffer et al. 2007). The local freshwater hosing immediately reduces local surface salinity, weakening the convection and sinking rates of deep-water formation and resulting in the slowdown of the AMOC, which in turn reduces the saline water advection from the south and enhances AMOC change. The positive feedback between the AMOC and meridional advection, that is, the classical Stommel advection mechanism, causes the AMOC to shutdown in decades. Both local and remote processes play critical roles, but at different stages of AMOC change. Surface freshwater forcing is the triggering mechanism, and the advection mechanism plays a critical role during the later stage.

The effect of surface buoyancy flux on the AMOC has been investigated comprehensively (Delworth et al. 1997; Eden and Willebrand 2001; Holland et al. 2001; Häkkinen and Rhines 2004; Jungclaus et al. 2005; Böning et al. 2006; Mignot et al. 2007; Stouffer et al. 2007; Swingedouw et al. 2007, 2009; Huang et al. 2012, 2014). However, how the wind stress affects the AMOC is less studied (Timmermann and Goosse 2004). The AMOC consists of wind-driven circulation (WDC) and thermohaline circulation (THC). These two components are tangled, and therefore hard to be separated. They can affect each other, and they both can be modulated by surface wind forcing (Weaver et al. 1993; Toggweiler and Samuels 1995; Schiller et al. 1997; Oka et al. 2001; Timmermann and Goosse 2004). Wind can induce horizontal Ekman flow and vertical Ekman pumping (Oka et al. 2001), thus affecting the WDC directly. Horizontal Ekman flow determines the saline water transport from the lower latitude (Timmermann and Goosse 2004) and is essential to maintain the THC. Ekman pumping can be an important factor in preconditioning oceanic convection (Killworth 1983; Schiller et al. 1997), thus affecting deep-water formation.

This paper revisits the fundamental question, that is, how would the AMOC respond to changes in ocean surface wind and freshwater flux, with a focus on wind effects. A fully coupled climate model is used. Sensitivity experiments are performed to separate the contributions of WDC and THC to the AMOC. The detailed processes that affect the AMOC at different stages are examined. Similar to previous studies, the wind forcing is crucial to both the WDC and THC in our model. However, different from existing studies (Schiller et al. 1997; Timmermann and Goosse 2004), our wind perturbation experiments emphasize the roles of vertical salinity diffusion and convection in triggering THC change, and suggest a positive feedback between THC strength and southward sea-ice expansion during the transient stage. When the wind forcing is reduced, vertical salinity diffusion and convection are weakened immediately in the mid-high latitudes of the Atlantic, resulting in an enhancement of vertical salinity stratification that restrains the deep-water formation there, triggering a slowdown of the THC. As the THC weakens, the sea ice expends southward and melts, supplying the upper ocean with fresh water that eventually shuts down the AMOC. It is found that in our wind perturbation experiments the WDC and THC have different preferential regions in terms of affecting salinity. The former affects the salinity in the subtropical and subpolar regions, while the latter affects the salinity mainly the GIN seas.

The main purpose of this paper is to explore wind effects on the THC. In an extreme situation with substantial wind forcing change over the ocean, the sea-ice feedback would emerge as an important factor to the THC change. This seaice positive feedback mechanism does not have to contradict the classical Stommel advection mechanism for the THC change (Swingedouw et al. 2007). The latter plays a major role when perturbing the ocean with freshwater flux. In different models or in different sensitivity experiments using the same model, the dominant mechanism can be different. This paper is arranged as follows. Section 2 introduces the coupled model and experiments. Section 3 describes the dynamic and buoyancy changes in the North Atlantic. Section 4 examines the mechanisms for the transient and equilibrium responses of the AMOC to wind perturbation. Section 5 is the summary and discussion.

\section{Model and experiments}

The model used in this study is the Community Earth System Model (CESM, version 1.0) of the National Center for 
Atmospheric Research (NCAR). CESM is a fully coupled global climate model that can provide state-of-the-art computer simulations of the Earth's past, present and future climate states (http://www2.cesm.ucar.edu/). CESM1.0 consists of five components and one coupler: the Community Atmosphere Model (CAM5; Neale et al. 2013), the Community Land Model (CLM4; Lawrence et al. 2012), the Community Ice CodE (CICE4; Hunke and Lipscomb 2008), the Parallel Ocean Program (POP2; Smith et al. 2010), the Community Ice Sheet Model (Glimmer-CISM), and the CESM Coupler (CPL7). CESM1.0 has been widely used and validated by researchers in the community (http:// journals.ametsoc.org/page/CCSM4/CESM1).

The model grid employed in this study is T31_gx3v7. The atmospheric component CAM5 has 26 levels in the vertical, with the finite volume nominal $3.75^{\circ} \times 3.75^{\circ}$ in the horizontal. The CAM5 is essentially a new version of the atmospheric model with improved, and more realistic, formulations of radiation, boundary layer and aerosols (Meehl et al. 2013; Neale et al. 2013). The general features of the model formulation can be found in Neale (2010) and Neale et al. (2013). CLM4 has the same horizontal resolution as CAM5. The ocean component of POP2 uses the grid gx3v7, which has 60 levels in the vertical. The ocean horizontal grid has a uniform $3.6^{\circ}$ spacing in the zonal direction and a non-uniform spacing in the meridional direction, which is $0.6^{\circ}$ near the equator, extends to the maximum of $3.4^{\circ}$ poleward of $35^{\circ} \mathrm{N} / \mathrm{S}$ and then decreases toward higher latitudes. The ocean model physics is described in detail in Danabasoglu et al. (2012). The sea-ice component of CICE4 has the same horizontal grid as POP2. No flux adjustments are used in CESM1.0.

Experiments that were carried out and analyzed in this study include a 2000-year control run, two 400-year windperturbation runs and two 400-year water-hosing runs. The control run (CTRL) starts from the rest using the standard configurations (http://www.cesm.ucar.edu/experiments/ cesm1.0/). The model climate of CTRL as a whole reaches a quasi-equilibrium after 1000 years of integration (Yang et al. 2014). In the wind-perturbation runs, the global surface wind stress forcing for the ocean model is artificially reduced to one-tenth (WIND0.1) and one-third (WIND0.3) of CTRL (Fig. 1a), respectively. The wind forcing in the sea-ice model and atmosphere model does not change, but the wind field will change in response to sea surface temperature (SST) change, which mainly comes from changes in oceanic circulations. We keep the wind forcing over the sea ice in the wind-perturbation experiments to avoid too strong and too quick changes in sea-ice movement and melting. The wind-perturbation experiments start from year 1501 of CTRL, and reach their quasi-equilibrium states after 400 years of integration. In the water-hosing experiments, the $0.1 \mathrm{~Sv}$ (HOSO.1) (Fig. 1b) and 1.0 Sv (HOS1.0) freshwater amounts are injected into the North Atlantic surface between 50 and $70^{\circ} \mathrm{N}$ for the whole integration (400 years), respectively. The monthly outputs are used for analysis. The climate changes in the wind-perturbation and water-hosing experiments are obtained by subtracting the corresponding fields from CTRL. Unless mentioned otherwise, the equilibrium change we refer to in this study is averaged over the last 200 years of each sensitivity experiment.

The model climatology from CTRL was carefully examined in Yang et al. (2014). The global ocean meridional overturning circulation, including the wind-driven Subtropical Cells (STCs) in the upper $500 \mathrm{~m}$ and the THC, and the mean thermal structure are well simulated in CESM1.0 (figures not shown). The STC in the Pacific has an antisymmetric structure about the equator as a result of the symmetric surface wind forcing in the tropics. The AMOC has a maximum of $20 \mathrm{~Sv}$, which is located at $40^{\circ} \mathrm{N}$ and near 1000-m depth. The Deacon Cell in the Southern Ocean has a maximum mass transport of about $20 \mathrm{~Sv}$, which is mostly confined in the Antarctic Circumpolar Current region (Döös and Webb 1994). The annual-mean thermal structure indicates reasonable simulation of the following feathers: equatorial thermocline strength, upwelling latitudes, subtropical shallow subduction region as well as the deep-water formation region in the North Atlantic high latitudes. The ocean barotropic streamfunction, the atmosphere Hadley Cells, the location of the intertropical convergence zone are also reasonably simulated. The model climatology of CESM1.0 has also been discussed in detail in many other documents (http://journals.ametsoc.org/page/CCSM4/CESM1).

\section{Changes in the Atlantic}

\subsection{AMOC changes}

Changes in both surface wind stress and freshwater flux can affect the AMOC significantly. Figure 2 shows the AMOC index in CTRL, and in the wind-perturbation and water-hosing runs. The AMOC index is defined as the maximum value of the streamfunction between $20-70^{\circ} \mathrm{N}$ and 300-2000 m in the Atlantic. In CTRL, the AMOC strength is around $18 \mathrm{~Sv}$. It is weakened quickly when the surface wind is reduced, or fresh water is added in the North Atlantic. The equilibrium response of the AMOC is about 2-4 Sv in the four sensitivity runs, depending on the strength of the modified external forcing. Under strong external forcing (e.g., 1.0 Sv freshwater hosing), the AMOC can reach a quasi-equilibrium state in 50 years; under weak forcing (e.g., $0.1 \mathrm{~Sv}$ freshwater hosing), it will take more than 100 years for the AMOC to reach its quasi-equilibrium state. In the wind perturbation experiments, the AMOC 
Fig. 1 a Wind stress forcing $\left(\mathrm{dyn} / \mathrm{cm}^{2}\right)$ used in CTRL; b freshwater forcing used in HOS0.1. For easy comparison, the $0.1 \mathrm{~Sv}$ freshwater hosing in the North Atlantic has been converted to virtual salt flux (psu/ month), by dividing the sea surface area between 50 and $70^{\circ} \mathrm{N}$ and the thickness of the first layer of the ocean model. The map in $\mathbf{b}$ is actually the virtual salt flux averaged over the first year integration of HOSO.1 (a) Wind stress $\left(\mathrm{dyn} / \mathrm{cm}^{2}\right)$

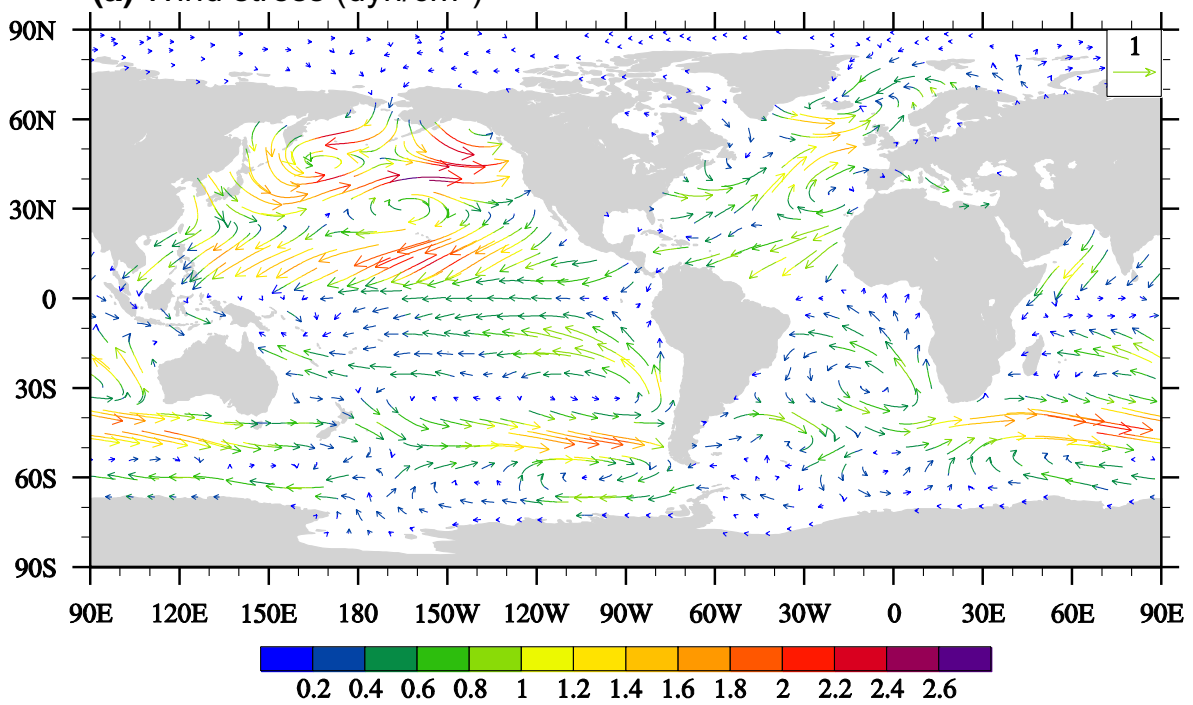

(b) Virtual salt flux (psu/month)

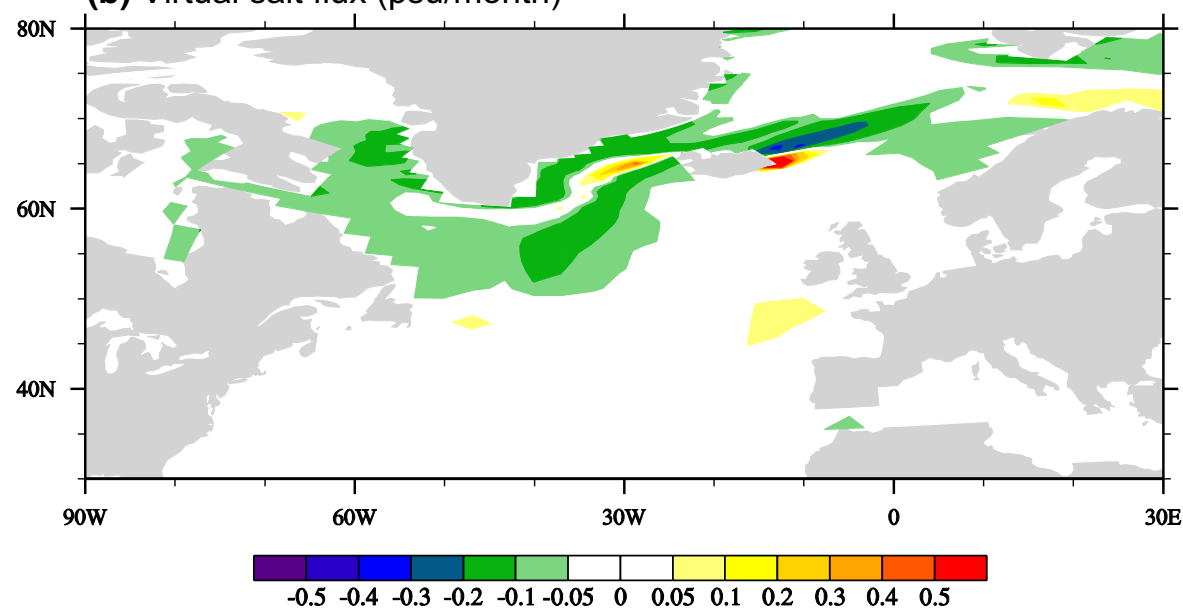

responds with a sudden overshooting in the first few years (solid blue and green curves in Fig. 2b). Previous studies suggested an opposite relationship between the changes in wind-driven STCs and THC (Hazeleger and Drijfhout 2006). The STC is reduced instantly within months in the wind perturbation experiments (dashed curves in Fig. 2b), while the THC remains unchanged. Therefore, the AMOC is strengthened slightly in the first few years in response to the reduced wind due to the immediate weakening of the STC.

The equilibrium change in the AMOC can be more clearly seen in Fig. 3. The AMOC has a maximum value at about $1000 \mathrm{~m}$ between 30 and $40^{\circ} \mathrm{N}$ in CTRL. The winddriven STC is clear in the upper $200 \mathrm{~m}$ and located on both sides of the equator (Fig. 3a). In HOS0.1, the THC is almost shut down while the STC is nearly unchanged (Fig. 3b). The latter is also seen in Fig. 2a (dashed orange curve). Therefore, the THC can be obtained by the difference between CTRL and HOS0.1. In WIND0.1, both the THC and STC are nearly shut down (Fig. 3c). The WDC can thus be defined as the difference between HOSO.1 and WIND0.1. In general, the AMOC can be roughly split into the THC and the WDC, with the help of these two sensitivity experiments. This separation will help us quantify the roles of the WDC and THC in AMOC change.

The AMOC changes in HOS1.0 and WIND0.3 are also examined. Figure 2a shows that the STC change in HOS1.0 is significant (red dashed curve). Unlike HOS0.1 where only $0.1 \mathrm{~Sv}$ fresh water is added to the North Atlantic, 1.0 Sv freshwater hosing in HOS1.0 is strong enough to affect surface ocean temperature and thus surface winds (not shown), which in turn causes significant change in the WDC. Figure $2 b$ shows similar changes in WIND0.1 and WIND0.3, but the remaining STC is stronger in WIND0.3 than in WIND0.1 (dashed green and blue curves, respectively). In this paper we will focus on HOSO.1 and 


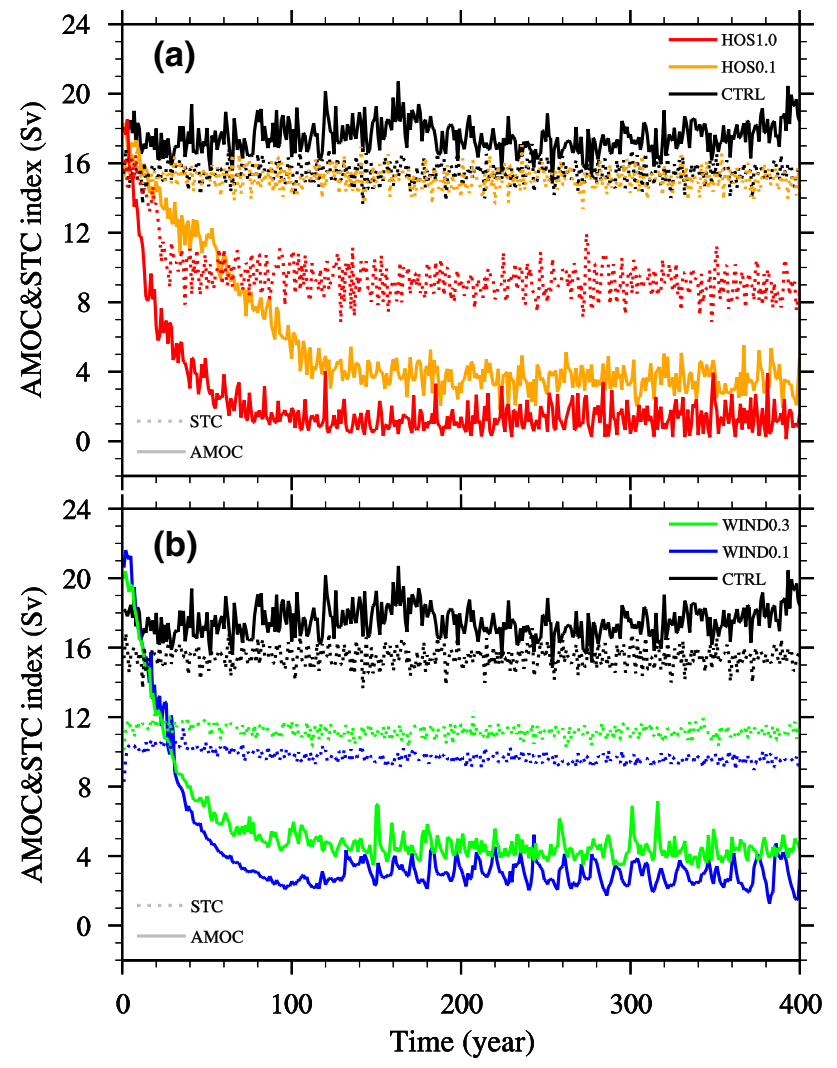

Fig. 2 Temporal evolutions of the AMOC and the Atlantic subtropical cell (STC) $\left(1 \mathrm{~Sv}=0^{6} \mathrm{~m}^{3} / \mathrm{s}\right)$. The AMOC index is defined as the maximum value of the streamfunction in the region of $20-70^{\circ} \mathrm{N}$, $300-2000 \mathrm{~m}$ in the Atlantic. The STC index is defined as the maximum value of the streamfunction in the region of $0-30^{\circ} \mathrm{N}, 0-100 \mathrm{~m}$ in the Atlantic. a Black curve is for CTRL; orange for HOS0.1 and red for HOS1.0. Solid curves are for the AMOC, and dashed ones for the STC. b Black curve is for CTRL; blue for WIND0.1 and green for WIND0.3. Solid curves are for the AMOC, and dashed ones for the STC

WIND0.1 since the AMOC changes are similar in these two experiments (orange curve in Fig. 2a and blue curve in Fig. 2b), and the THC and WDC can be better separated using these two runs.

\subsection{Splitting horizontal ocean circulation}

Figure 4 shows the mean horizontal ocean circulation averaged in the top $30 \mathrm{~m}$ in the Atlantic, of which the total circulation is split into the THC, the WDC and the residual circulation. The THC (Fig. 4a) is obtained from the difference between CTRL and HOSO.1, since the WDC in HOSO.1 can be thought as unchanged (Fig. 3b). The WDC (Fig. 4b) is obtained by subtracting the circulation in WIND0.1 from that in HOS0.1. Keep in mind that in WIND0.1, there is still very weak WDC since the wind forcing is not completely shut down. Figure $4 \mathrm{~b}$ represents roughly $90 \%$ of (a) CTRL

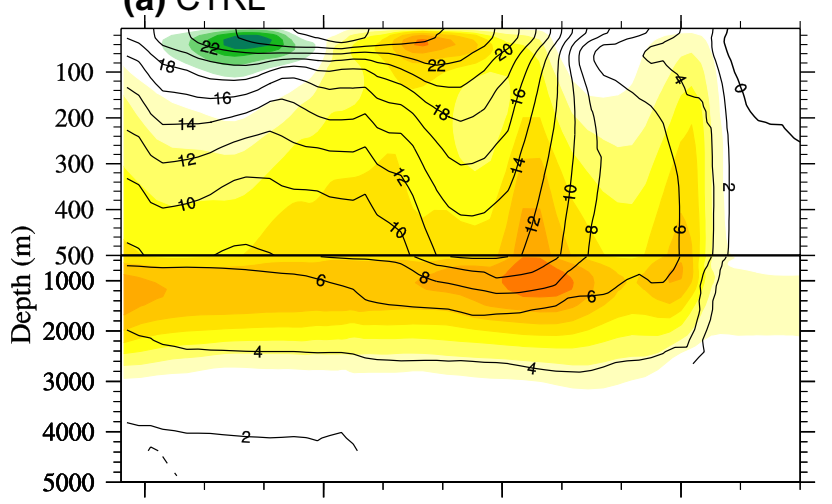

(b) HOS0.1

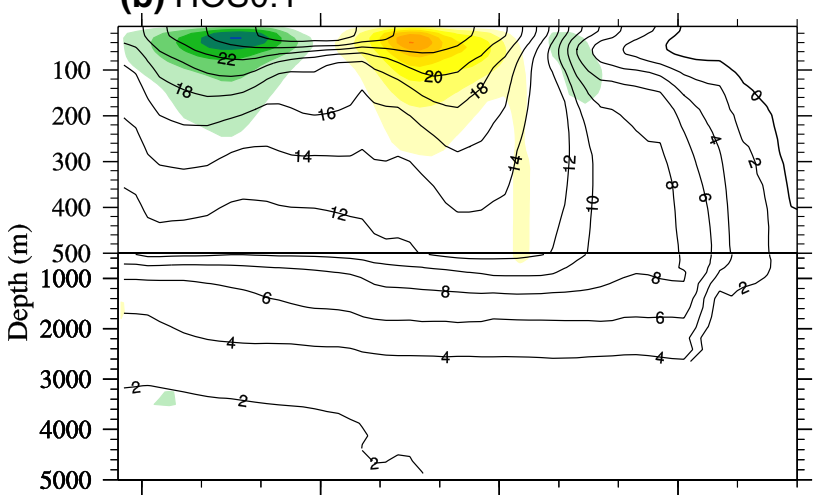

(c) WIND0.1

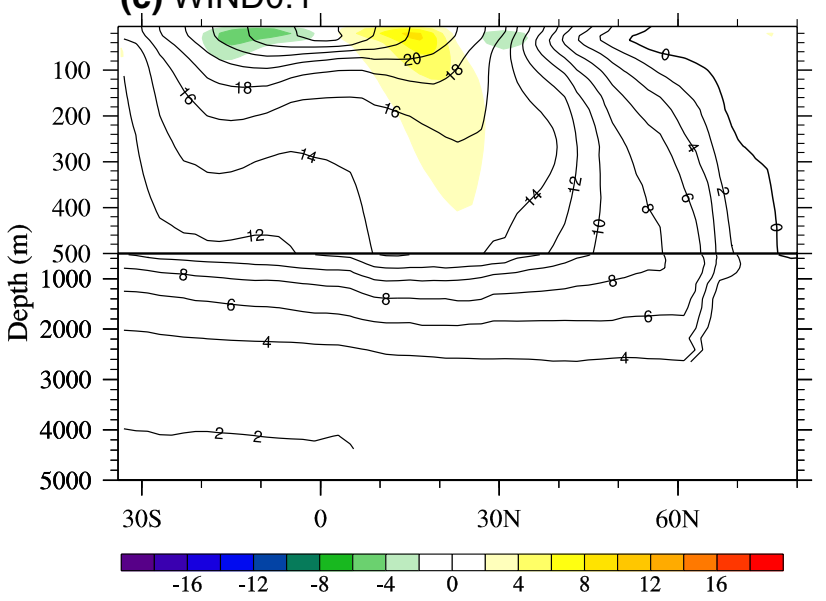

Fig. 3 The mean AMOC (color, Sv) superimposed by zonal-mean potential temperature in the Atlantic (contours; ${ }^{\circ} \mathrm{C}$ ), averaged over the last 200 years of each experiment: a CTRL, b HOS0.1 and c WIND0.1

the WDC. The residual circulation (Fig. 4c) is the circulation left in WIND0.1, representing the Goldsbrough (1933) circulation forced by the net surface freshwater flux (i.e., surface evaporation minus precipitation, EMP).

The surface pattern of the THC exhibits the main features of the surface conveyor belt (Fig. 4a). There is a systematic northward flow from the South Atlantic, which appears to 
(a) THC

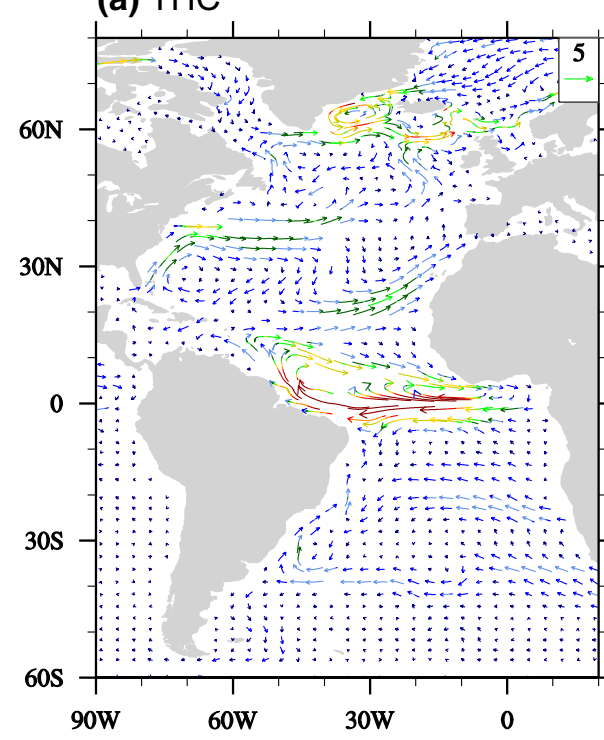

(b) WDC

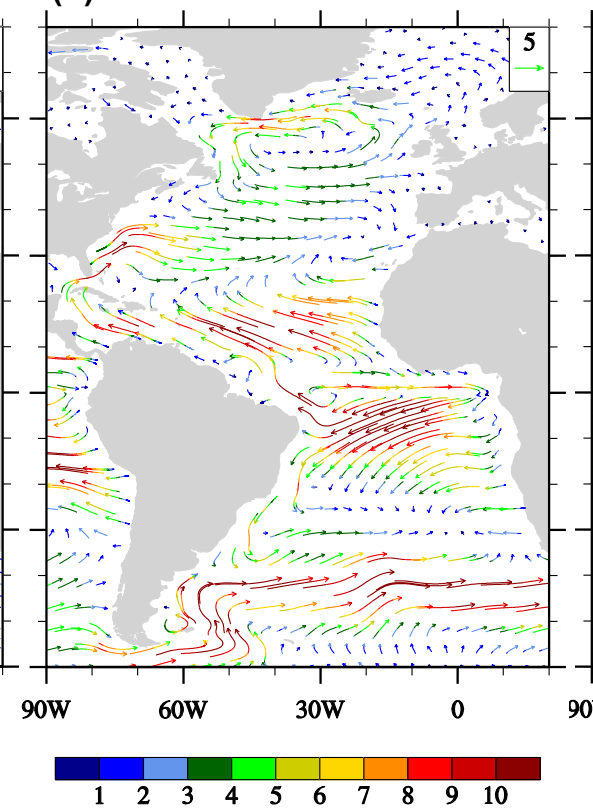

(c) Residual

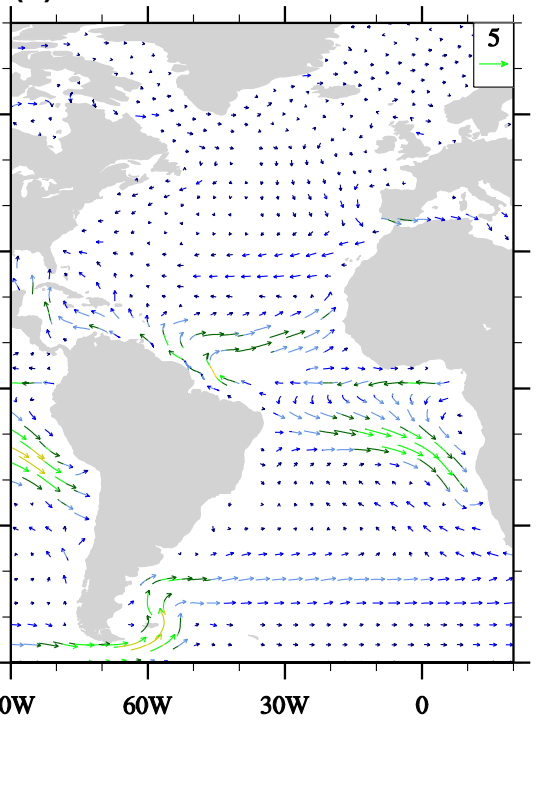

Fig. 4 The mean ocean circulation averaged in the top 30-m depth $(\mathrm{cm} / \mathrm{s})$. It has been split into a the thermohaline, $\mathbf{b}$ the wind-driven and $\mathbf{c}$ the residual (EMP) parts. The mean pattern is obtained by averaging model output over the last 200 years of each experiment

connect with the flows from the southern Indian Ocean. Moreover, we see the strong Brazil Current in the North Atlantic, turning into two major branches near $20^{\circ} \mathrm{N}$ : one branch flows northward along the western boundary and then turns northeastward to the high latitudes; the other branch flows eastward and then northward along the eastern boundary. These two branches merge in the GIN seas. The WDC pattern is featured by the subtropical gyre, the subpolar gyre and the Antarctic Circumpolar Current (Fig. 4b). We can see that the THC tends to reinforce the Gulf Stream transport whereas it slows down the subpolar gyre, similar to the finding of Timmermann and Goosse (2004). The Goldsbrough circulation (Fig. 4c) is very weak in most regions except near the equator. North of the equator, the surface Goldsbrough flow is similar to the THC. South of the equator, it flows against both the THC and WDC. Clearly, on the $\mathrm{O}(1)$ approximation, as shown in Fig. 3, the freshwater hosing in the North Atlantic can only affect the THC, while the change in surface wind stress can affect both THC and WDC. The decomposition of the upper-ocean circulation in Fig. 4 can help us quantify the contributions of different circulations to salinity and temperature fields.

\subsection{Salinity and temperature advections by THC and WDC}

Many studies have shown that wind stress maintains the meridional salt advection, preventing the formation of the halocline in the high latitudes (Oka et al.
2001; Timmermann and Goosse 2004; Arzel et al. 2009). Salinity advection was thought as one of the key factors in maintaining the AMOC. In this study, the salinity (temperature) advections by THC and WDC are $S_{T H C}=-\vec{V}_{T H C} \cdot \nabla S \quad$ and $\quad S_{W D C}=-\vec{V}_{W D C} \cdot \nabla S$ $\left(T_{T H C}=-\vec{V}_{T H C} \cdot \nabla T\right.$ and $\left.T_{W D C}=-\vec{V}_{W D C} \cdot \nabla T\right)$, respectively. $\vec{V}_{T H C}\left(\vec{V}_{W D C}\right)$ is the velocity vector obtained in Fig. 4a (Fig. 4b) and the salinity (temperature) gradient $\nabla S(\nabla T)$ is obtained from CTRL. The total salinity (temperature) advection is $S_{a d v}^{c t r l}=-\vec{V}_{c t r l} \cdot \nabla S \approx S_{T H C}+S_{W D C}$ $\left(T_{a d v}^{c t r l}=-\vec{V}_{c t r l} \cdot \nabla T \approx T_{T H C}+T_{W D C}\right)$.

Our experiments show that the THC and WDC have opposite effects on the salinity and temperature fields in the North Atlantic (Fig. 5). In the high latitudes $\left(50-70^{\circ} \mathrm{N}\right)$, the THC advection has significant freshening and cooling effects on the Labrador Sea and the region southeast to the Greenland, and has weak salinification and warming effects on the seas north and west of Iceland (Fig. 5a, d). The WDC advection, on the contrary, has significant salinification and warming effects (Fig. 5b, e), and eventually determines the salinity and temperature tendencies there (Fig. $5 \mathrm{c}$, f). In the mid-latitudes between 30 and $50^{\circ} \mathrm{N}$, the WDC advection has strong freshening and cooling effects (Fig. 5b, e), which can be slightly offset by weak salinification and warming effects by the THC advection (Fig. 5a, d). In the tropics, both WDC and THC advections have the same effect on the surface salinity and temperature fields. Overall, for the upper-layer buoyancy field, the WDC advection dominates over the THC advection in the entire Atlantic (Fig. 5b, c, e, f). 


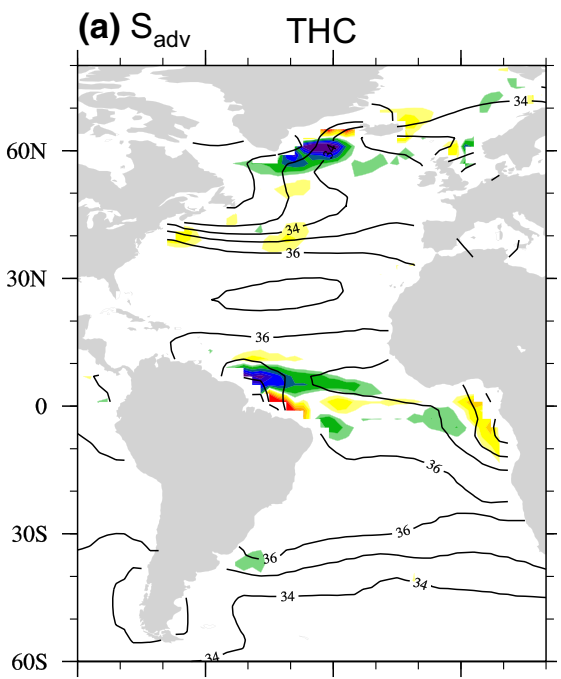

(d) $T_{\text {adv }}$

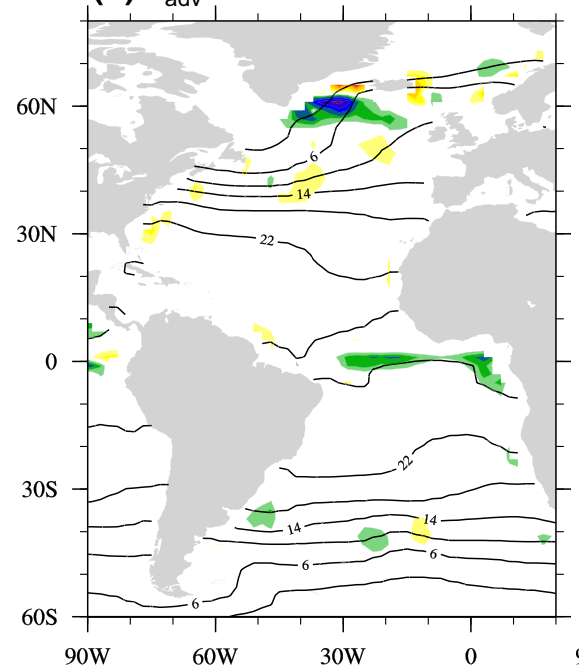

(b)

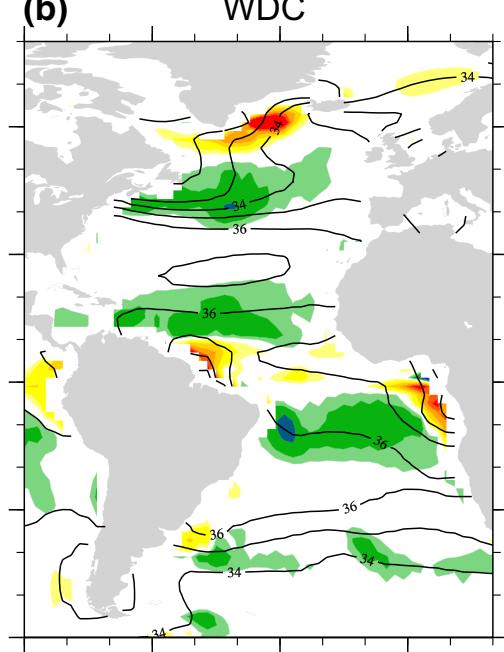

(e)

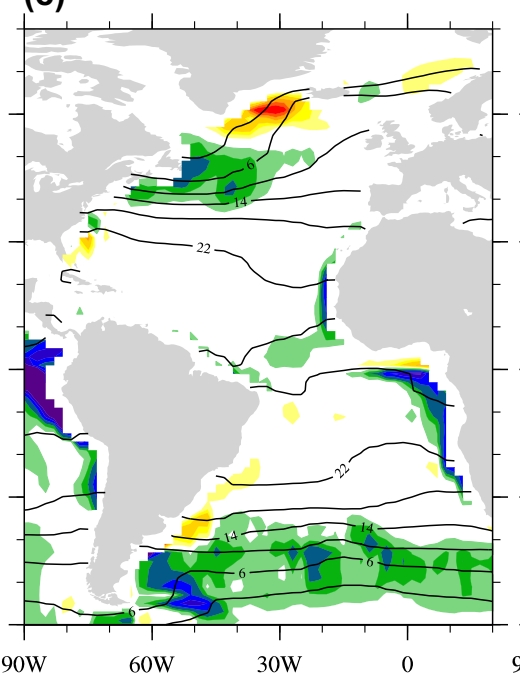

(c) Total

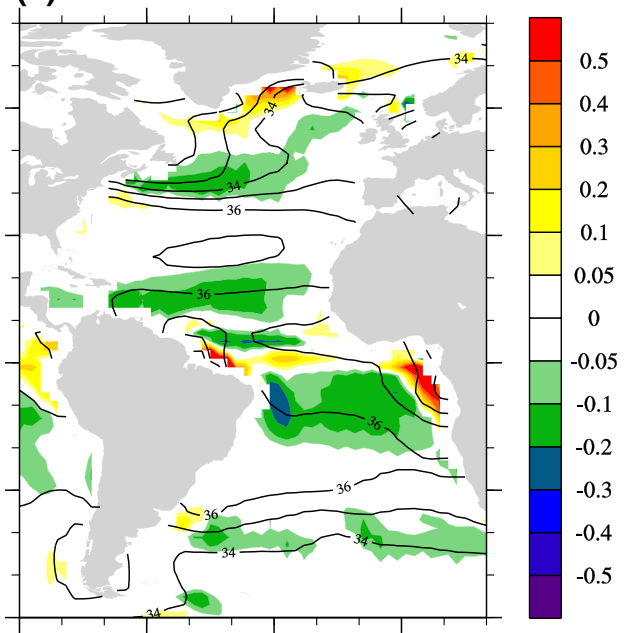

(f)

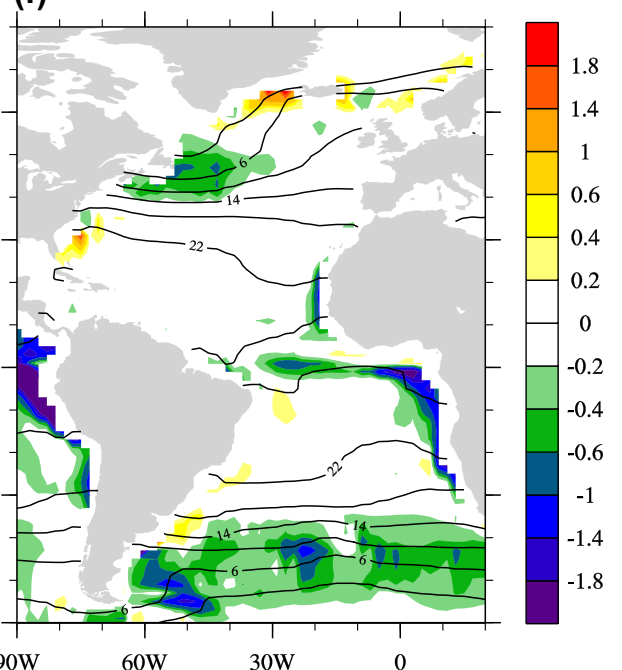

Fig. 5 Top panels salinity advection (psu/month) averaged in the top 30-m depth, split into a the thermohaline and $\mathbf{b}$ the wind-driven parts. c The total advection. Bottom panels same as the top panels, except for temperature advection $\left({ }^{\circ} \mathrm{C} /\right.$ month). The mean surface (top)

In WIND0.1, the salinity and temperature advections are almost shut down because $\vec{V}_{\text {wind } 0.1} \approx 0$. Therefore, the advection changes in WIND0.1 $\Delta S_{a d v}^{\text {wind } 0.1}=S_{a d v}^{\text {wind } 0.1}-S_{a d v}^{c t r l} \approx-S_{a d v}^{c t r l}=\vec{V}_{c t r l} \cdot \nabla S$

and $\quad \Delta T_{a d v}^{\text {wind } 0.1}=\vec{V}_{c t r l} \cdot \nabla T$, which are almost totally caused by the perturbation circulation $\left(d \vec{V}=\vec{V}_{\text {wind } 0.1}-\vec{V}_{c t r l} \approx-\vec{V}_{c t r l}\right)$ and have an opposite sign to that shown in Fig. $5 \mathrm{~b}$, e. The contributions from changes in salinity and temperature can be neglected because $\quad\left|\Delta S_{a d v}^{\text {wind } 0.1}\right|=\left|\vec{V}_{c t r l} \cdot \nabla S\right| \gg\left|\vec{V}_{c t r l} \cdot \nabla S^{\prime}\right| \quad$ and $\left|\Delta T_{a d v}^{\text {wind } 0.1}\right|=\left|\vec{V}_{c t r l} \cdot \nabla T\right| \gg\left|\vec{V}_{c t r l} \cdot \nabla T^{\prime}\right| . \quad$ This $\quad$ can be seen in Fig. 5b, c, e, f. In general, the perturbation salinity (psu) and (bottom) temperature $\left({ }^{\circ} \mathrm{C}\right)$ from CTRL are superimposed using contours. The patterns are obtained by averaging model outputs over the last 200 years of each experiment

advection mechanism is more important than the mean advection mechanism in WIND0.1, but none of them plays a major role in the North Atlantic surface freshening.

\subsection{Buoyancy responses}

The salinity, temperature and density changes in HOSO.1 and WIND0.1 are examined in Figs. 6 and 7. For HOS0.1, it is straightforward that the North Atlantic surface freshening (Figs. 6a, 7a) is mainly due to the freshwater hosing in the high latitudes (Fig. 1b). The ceasing of the THC salinity advection from the tropics also contributes to the surface freshening in the mid-latitudes, as implied by Fig. 5a. The shutdown of THC results in a significant 
(a) $\Delta S$

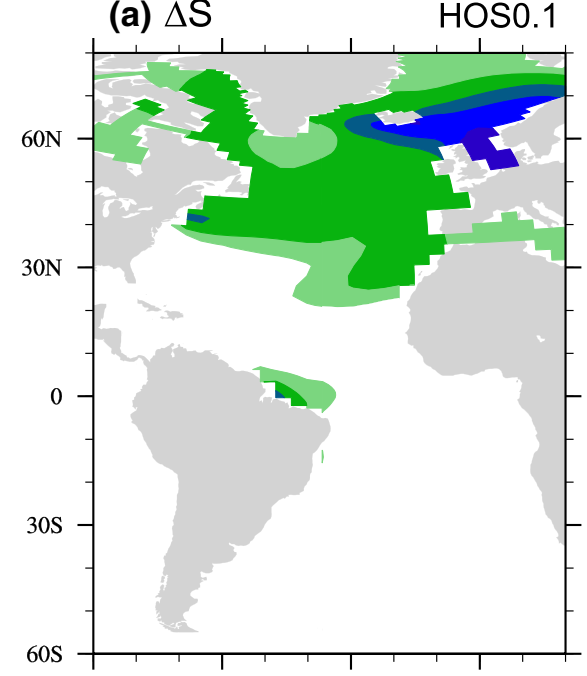

(d) $\Delta \mathrm{S}$

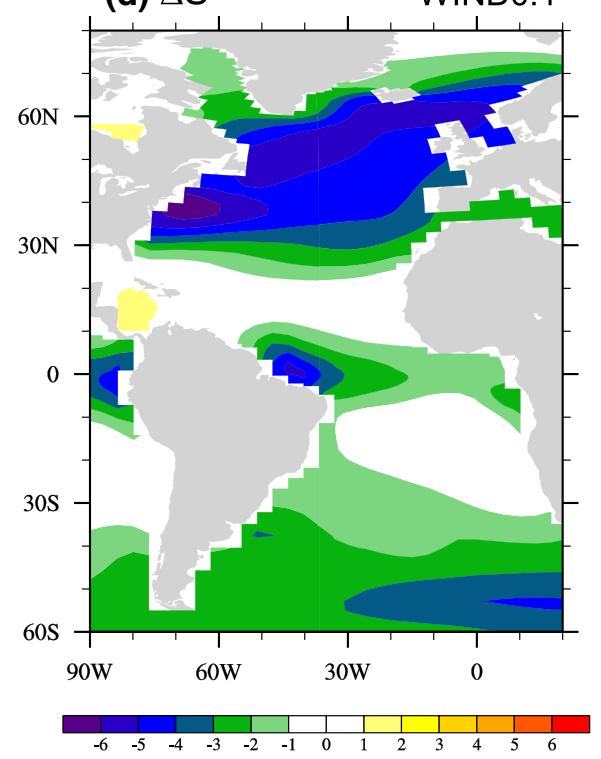

(b) $\Delta \mathrm{T}$

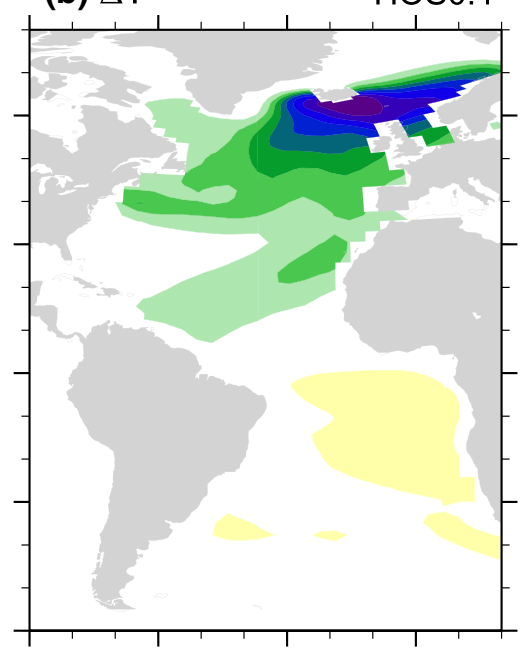

(e) $\Delta \mathrm{T}$

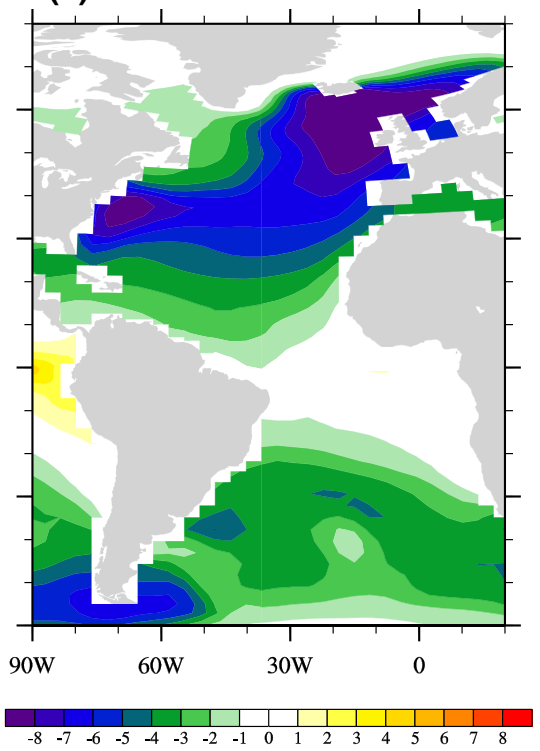

(c) $\Delta \sigma$

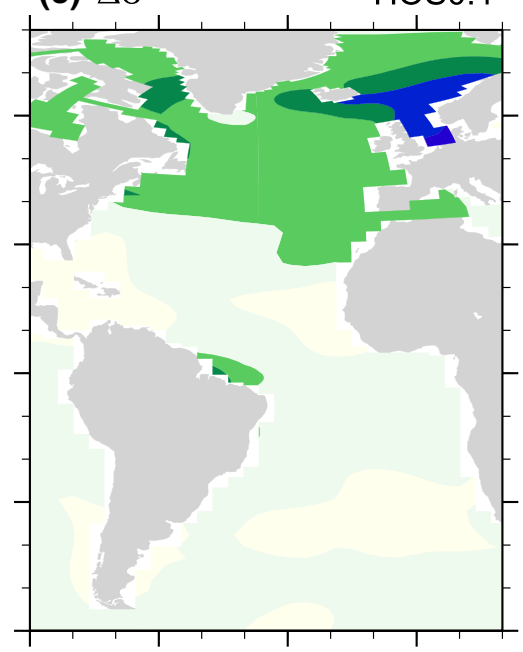

(f) $\Delta \sigma$

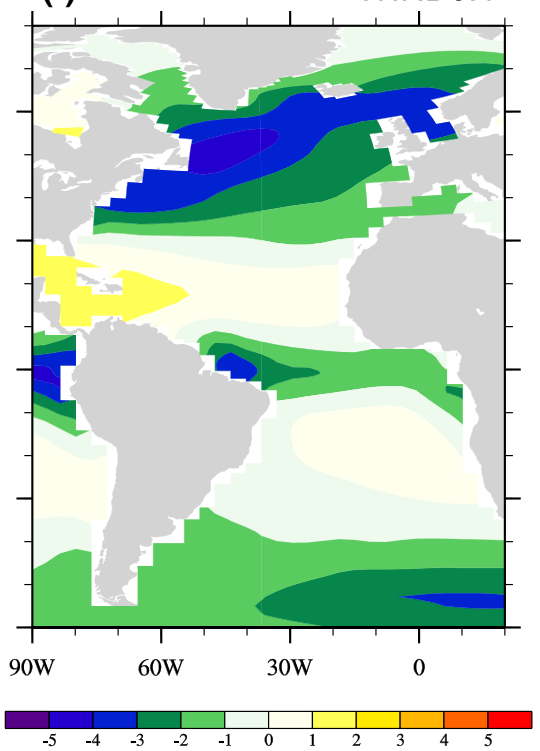

Fig. 6 Buoyancy changes averaged in the top 30-m layer. a, d for salinity (psu); b, e for temperature $\left({ }^{\circ} \mathrm{C}\right) ; \mathbf{c}, \mathbf{f}$ for density $\left(\mathrm{kg} / \mathrm{m}^{3}\right)$. Top panels are from HOS0.1, and bottom panels, from WIND0.1. The mean state from CTRL is removed. The mean pattern is obtained by averaging model output over the last 200 years of each experiment

The buoyancy change is much more significant in WIND0.1 than in HOS0.1 (Figs. 6d-f, 7d-f). This is because both the THC and WDC are shut down in WIND0.1. The shutdown of the Atlantic WDC causes further deficit of salt and heat in the North Atlantic upper ocean. Moreover, the salinity and temperature in the South Atlantic upper ocean are also decreased significantly. The anti-symmetric change in HOSO.1 turns to the symmetric change in WIND0.1, because the WDC is roughly symmetric about the equator.

The WDC effect is only significant for the upper ocean, while the change in the lower ocean is mainly associated with the THC effect (Fig. 7). We can see that the changes in 
(a) $\Delta \mathrm{S}$

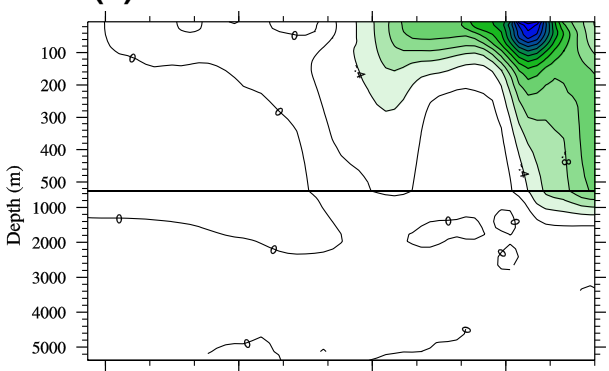

(d) $\Delta \mathrm{S}$

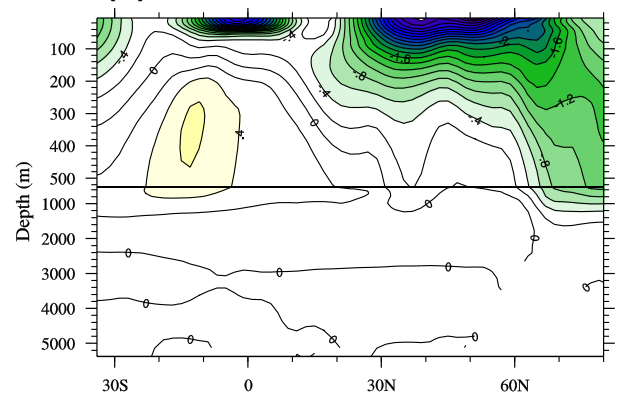

(b) $\Delta T$

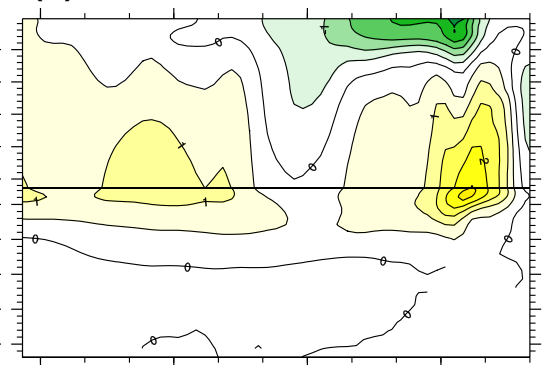

(e) $\Delta T$

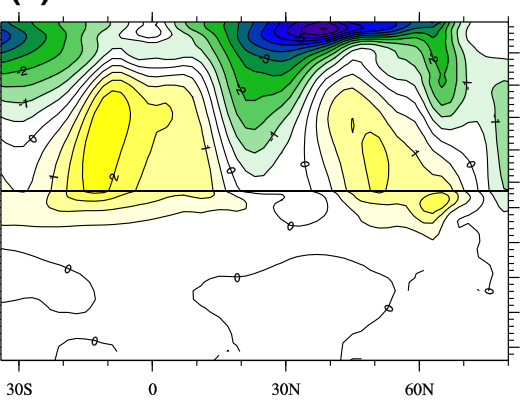

(c) $\Delta \sigma$

HOSO.1

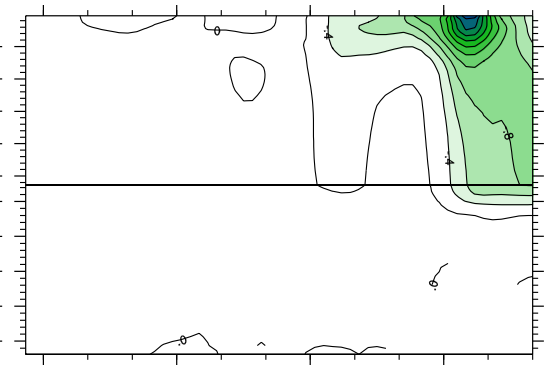

(f) $\Delta \sigma$

WIND0.1

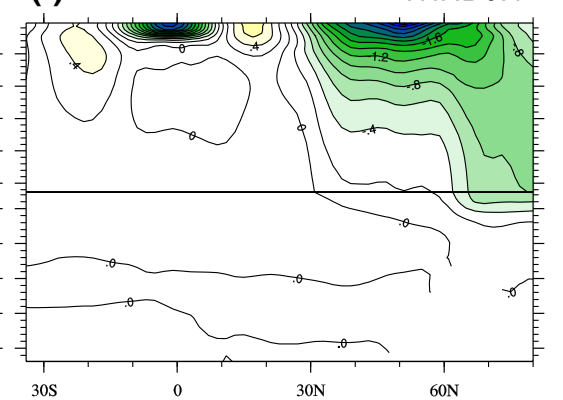

Fig. 7 Same as Fig. 6, except for zonally-averaged buoyancy changes in the Atlantic

salinity, temperature and density below $200 \mathrm{~m}$ in HOS0.1 are similar to those in WIND0.1, which suggests the dominant role of the THC in subsurface ocean. The significant baroclinic response in the high latitudes of the North Atlantic occurs in both HOS0.1 and WIND0.1, with strong cooling in the surface and modest warming in the deeper ocean (Fig. 7b, e), consistent with previous studies (e.g., Chang et al. 2008). Here, we can again see that the density change in WIND0.1 (Fig. 7f) is predominantly determined by salinity change (Fig. 7d). This is particularly clear in the extratropics, where the temperature cooling should have resulted in density increase. Therefore, to reveal the mechanism of AMOC change in WIND0.1, we need to focus on the mechanism for salinity change.

Unlike the salinity change in HOSO.1 where the external freshwater flux plays a dominant role, the salinity change in WIND0.1 has to be related to ocean dynamics and sea-ice dynamics. Figure $5 \mathrm{~b}$ shows that the WDC advection plays a crucial role in buoyancy balance in the North Atlantic. Without the WDC advection in WIND0.1, the salinity in the high latitudes $\left(50-70^{\circ} \mathrm{N}\right)$ would decrease (Fig. 5b). This is consistent with the freshening in the GIN seas and Labrador Sea (Fig. 6d). However, in the region between $30-50^{\circ} \mathrm{N}$ the surface ocean freshening cannot be explained by the advection mechanism, because the weakening of WDC advection in WIND0.1 turns out to be a salinification factor to the surface ocean (Fig. 5b). This is inconsistent with the actual freshening in WIND0.1 (Fig. 6d). Furthermore, although the
WDC weakening causes a warming tendency in the midlatitudes (Fig. 5e, f), it does not contribute to the density decrease there, because strong cooling actually occurs in the North Atlantic (Fig. 6e). Therefore, there must be other mechanisms responsible for the freshening and density decrease in the mid-latitudes in WIND0.1. As we will see next, sea-ice melting is found to play a critical role.

\subsection{Mixed layer depth changes}

The mean March mixed layer depth (MLD) is examined here (Fig. 8). Sites of the deepest vertical mixing and convection can be found in the mean March MLD (Brady and Otto-Bliesner 2010). The MLD is defined as the shallowest depth where the local, interpolated buoyancy gradient matches the maximum buoyancy gradient between the surface and any discrete depth within that water column (Large et al. 1997). In CTRL, the main convection and vertical mixing sites are found south of Greenland, and in the GIN seas (Fig. 8a). The MLD becomes shallower in both HOS0.1 and WIND0.1 (Fig. 8b, c), in association with strengthened vertical buoyancy stratification (Fig. 7c, f). Without the THC, the MLD in the GIN seas is reduced by more than $500 \mathrm{~m}$ (Fig. 8d). Without the WDC, the MLD is reduced by about $20-100 \mathrm{~m}$ in the mid-latitudes between 30 and $60^{\circ} \mathrm{N}$ (Fig. 8f). The shallower MLD signals the weakening of convection, vertical mixing and diffusion, and thus the deep-water formation: it occurs in the 
(a) CTRL

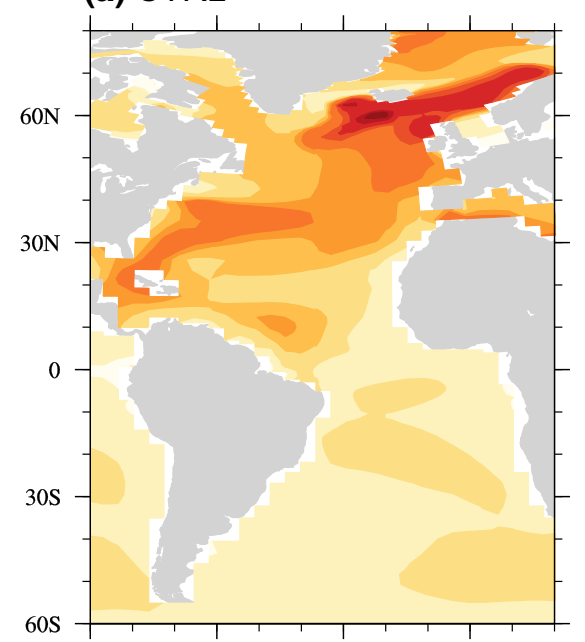

(d) HOS0.1-CTRL

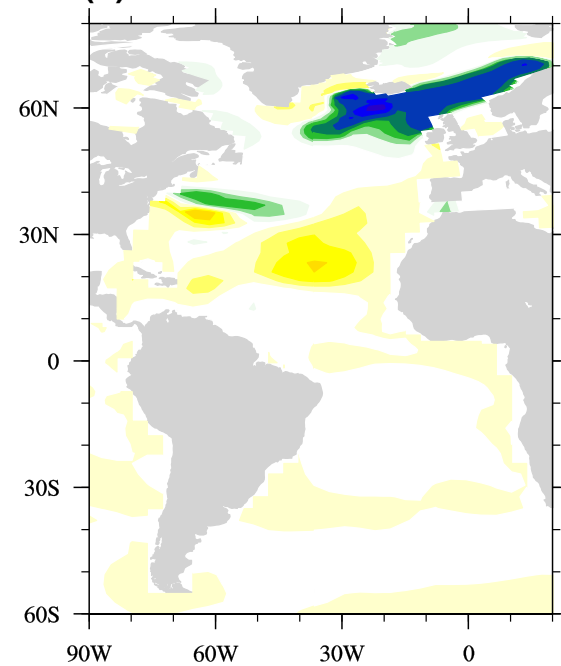

(b) HOSO.1

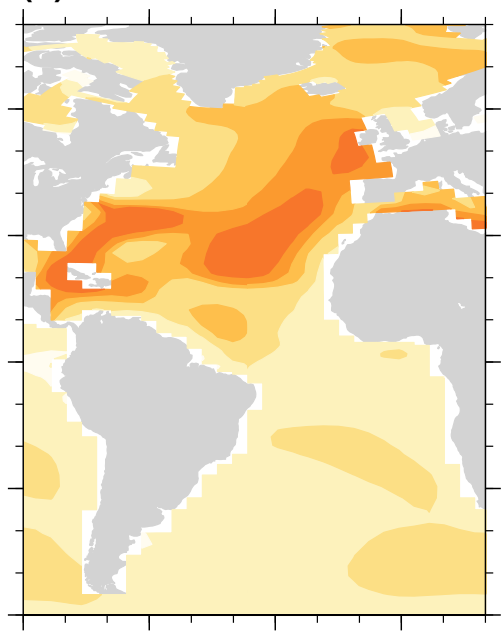

(e) WIND0.1-CTRL

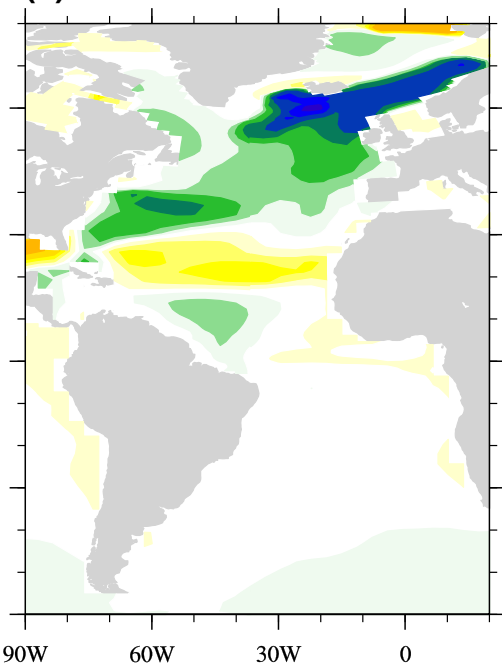

(c) WIND0.1

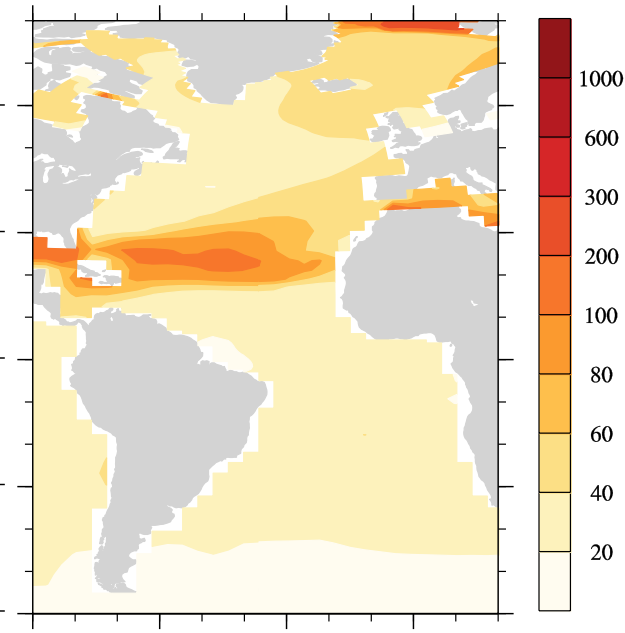

(f) WIND0.1-HOS0.1

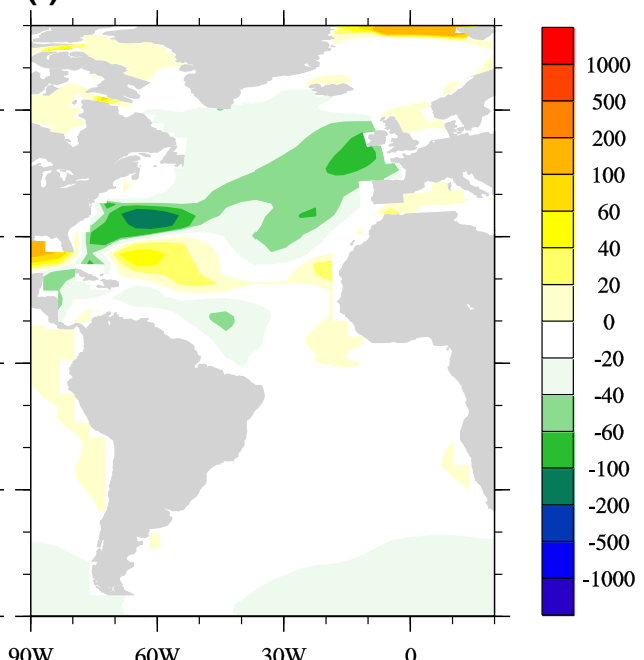

Fig. 8 Top panels mean March mixed layer depth (MLD; m) in the Atlantic in a CTRL, b HOS0.1 and $\mathbf{c}$ WIND0.1. Bottom panels MLD changes in $\mathbf{d}$ HOS0.1, $\mathbf{e}$ WIND0.1 and $\mathbf{f}$ the difference between

high latitudes $\left(60^{\circ} \mathrm{N}\right.$ and beyond) in HOS0.1 (Fig. 8d), and between 30 and $60^{\circ} \mathrm{N}$ in WIND0.1 (Fig. 8e).

The changes in MLD and surface salinity in WIND0.1 are remarkable in the region of $30-70^{\circ} \mathrm{N}$. We can see that although the largest MLD change occurs mainly in the GIN seas (Fig. 8e), the biggest density change occurs mainly in the lower latitudes between 40 and $60^{\circ} \mathrm{N}$ (Fig. 6f) in WIND0.1. Previous studies suggested similar situation (e.g., Brady and Otto-Bliesner 2010). We will see in the next section that the biggest sea-ice melting also occurs in the region between 40 and $60^{\circ} \mathrm{N}$ in WIND0.1. The changes in MLD shown in Fig. 8 is the result of sea-ice melting, weakened wind stirring and vertical mixing, among others. In the next section, we will focus on discussing changes in this region.
WIND0.1 and HOS0.1. f The MLD change without the WDC. The mean pattern is obtained by averaging model output over the last 200 years of each experiment

\section{Mechanisms}

\subsection{For equilibrium responses}

Figure 9 shows the annual-mean fields of sea-ice formation, sea-ice velocity and sea-ice margin. Sea-ice formation is defined as the sum of ice formation (melting) in the ocean and the ice from the continent, which is then converted to virtual salt flux (psu/month) for easy comparison with the salinity advection shown in Fig. 5a-c. Sea-ice margin is defined as the $15 \%$ sea-ice fraction in the Atlantic.

The freshening in the mid-latitude ocean surface in WIND0.1 is mainly due to sea-ice melting (Fig. 9d). The reduction of ocean surface wind can result in significant 
(a) CTRL

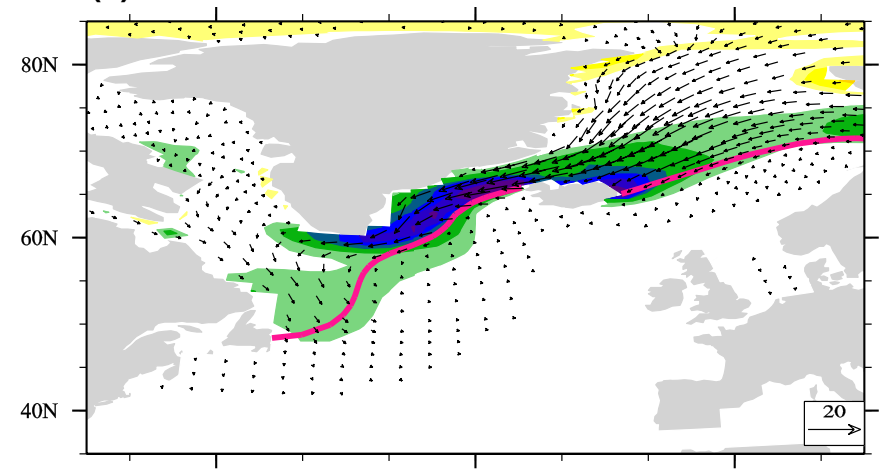

(b) WIND0.1

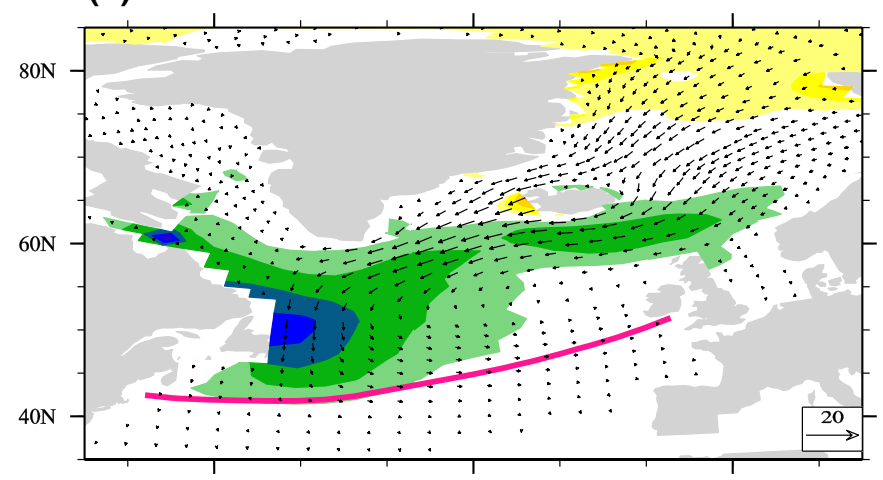

(c) HOSO.1

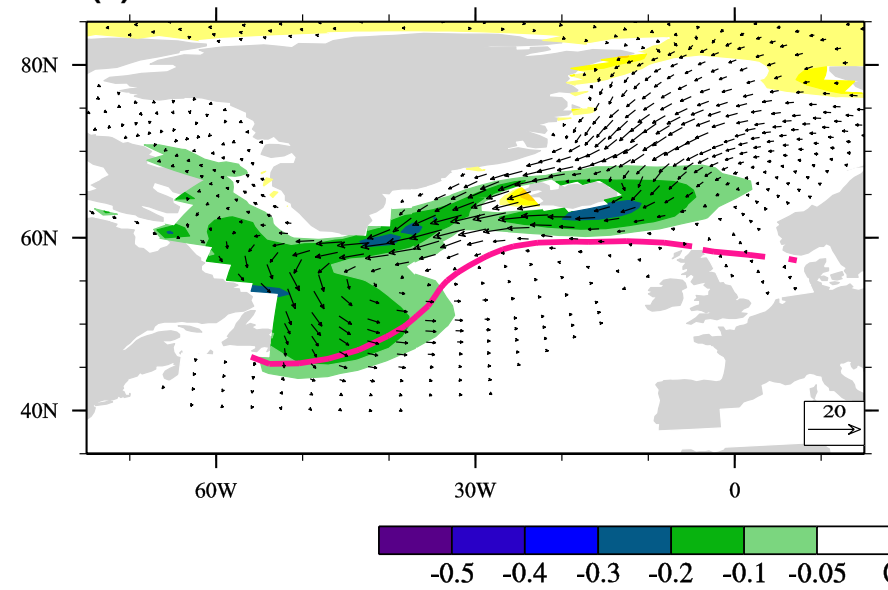

(d) WIND0.1-CTRL

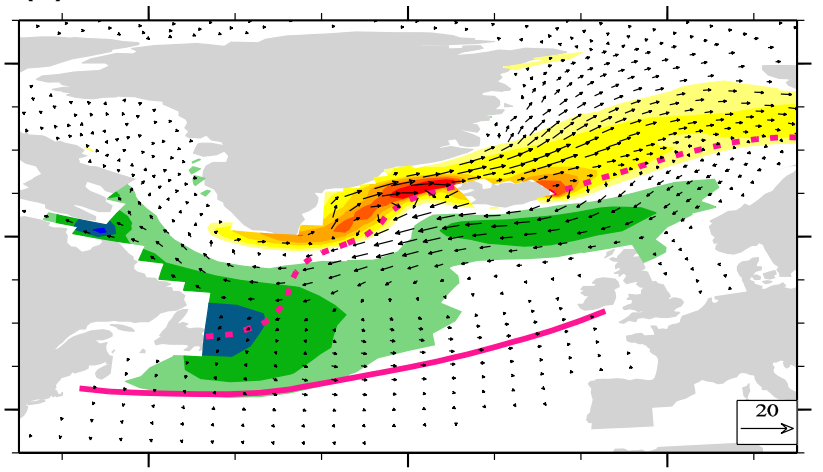

(e) HOS0.1-CTRL

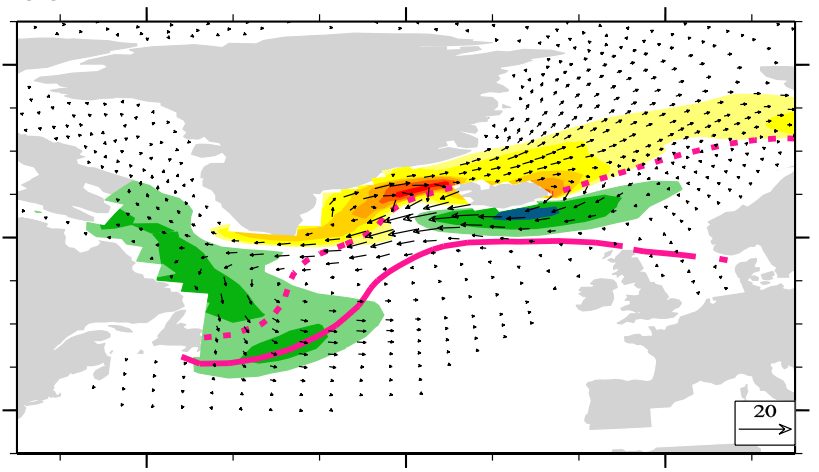

(f) WIND0.1-HOS0.1

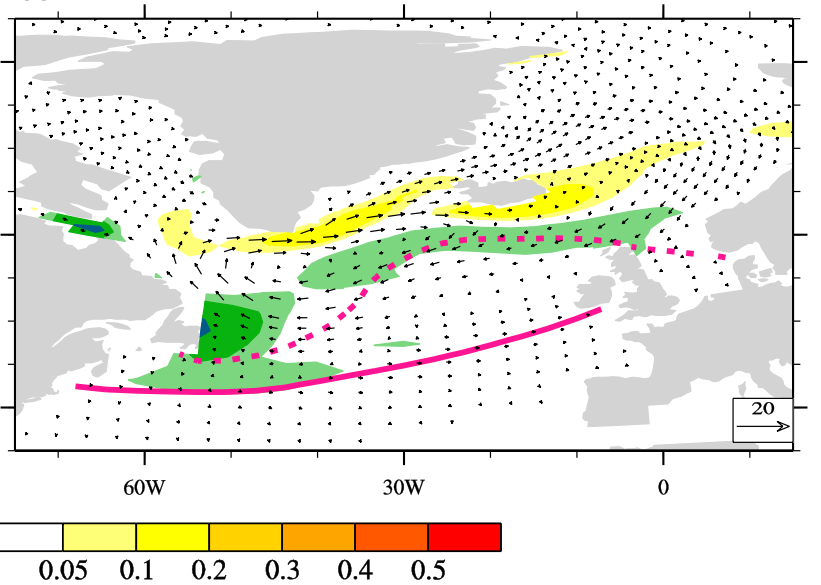

Fig. 9 Left panels annual mean sea-ice formation (color; psu/month), sea-ice velocity (vector; $\mathrm{cm} / \mathrm{s}$ ) and sea-ice margin (red curve) defined by the $15 \%$ sea-ice fraction in the Atlantic. a For CTRL; b for WIND0.1 and c for HOS0.1. Negative sea-ice formation means seaice melting, which has been converted to virtual salt flux by multiplying $\mathrm{S}_{0} /\left(\rho_{0} \mathrm{H}\right)$, where $\mathrm{S}_{0}(35)$ is the reference salinity, $\rho_{0}$ is the mean seawater density and $H$ is the upper-layer thickness $(30 \mathrm{~m})$. Right

southward expansion of sea ice and thus melting (Fig. 9b). The enhanced sea-ice melting in WIND0.1 is clear in the mid latitudes between 40 and $60^{\circ} \mathrm{N}$ (Fig. 9d), whose pattern is in good agreement with that of salinity change (Fig. 6d). In the high latitudes (north of $60^{\circ} \mathrm{N}$ ), there is strong sea-ice panels their changes in $\mathbf{d}$ WIND0.1, e HOS0.1 and $\mathbf{f}$ the difference between WIND0.1 and HOS0.1, which represents the sea-ice changes due to $\mathbf{d}$ the lack of both thermohaline and wind-driven circulations, $\mathbf{e}$ the lack of the thermohaline circulation and $\mathbf{f}$ the lack of the winddriven circulation. The dashed (solid) red curve in $\mathbf{d}$, e represents the sea-ice margin in CTRL (WIND0.1 and HOS0.1). The dashed (solid) curve in $\mathbf{f}$ represents the sea-ice margin in HOS0.1 (WIND0.1)

formation in WIND0.1, which tends to increase surface salinity (Fig. 9d). Sea-ice melting into the North Atlantic can lead to considerable change in deep-water formation. This has been reported in previous studies (Oppo and Lehman 1995; Vidal et al. 1997; Elliot et al. 2002; 
McManus et al. 2004). We can see that the sea-ice margin expands southward by near $20^{\circ}$ latitudes from $\sim 60^{\circ} \mathrm{N}$ in CTRL to $\sim 40^{\circ} \mathrm{N}$ in WIND0.1, accompanied by enhanced southward sea-ice movement (Fig. 9b, d), while the southward sea-ice movement between the Greenland and Iceland is greatly reduced.

The sea-ice margin is always close to the main convection site. In CTRL, the main convection site is located in the GIN seas (Fig. 8a) and the sea-ice margin is mainly along $60^{\circ} \mathrm{N}$ (Fig. 9a). In WIND0.1, the sea-ice margin moves to nearly $40^{\circ} \mathrm{N}$ (Fig. 9b, d), so does the main convection site that moves southward to $30^{\circ} \mathrm{N}$ (Fig. 8c). The sea-ice melting reduces the surface seawater density and thus the convection. So, the main convection site is not right on the edge of sea ice, but to the south of sea-ice edge. This is clearly shown in WIND0.1 and HOS0.1 (Figs. 8c vs. 9b, d; Figs. 8b vs. 9c, e). Here, we would like to emphasize that the change of convection site is the result of seaice melting, which would not feedback to sea-ice melting.

The sea-ice movement is driven by stress difference between ice-air interface and ice-water interface. According to Hunke and Lipscomb (2008), the net stress is given as follows:

$\vec{\tau}_{i}^{\text {net }}=\vec{\tau}_{i}^{a}+\vec{\tau}_{i}^{o} \propto\left|\vec{u}_{a}\right| \vec{u}_{a}+\left|\vec{u}_{o}-\vec{u}_{i}\right|\left(\vec{u}_{o}-\vec{u}_{i}\right)$,

where $\vec{\tau}_{i}^{\text {net }}$ is the net stress force on sea ice; $\vec{\tau}_{i}^{a}$ is the airice interface stress; and $\vec{\tau}_{i}^{o}$ is the ocean-ice interface stress. $\vec{u}_{a}, \vec{u}_{o}$ and $\vec{u}_{i}$ are surface air speed, surface ocean current speed and sea-ice movement speed, respectively. First of all, the wind stress on sea ice does not change $\left(\vec{u}_{a} \approx\right.$ const. $)$ in all experiments. Second, the ocean current velocity in WIND0.1 is reduced $\left(\vec{u}_{o} \approx 0\right)$. Therefore, in the GIN seas where the ice velocity has the same direction as the ocean current (Fig. 4b, Fig. 9a), the sea-ice velocity is also weakened greatly in WIND0.1 (Fig. 9b) due to weakened stress from the ocean, showing a strong anomalous northward drift (Fig. 9d). In the region between 40 and $60^{\circ} \mathrm{N}$, the ocean current is eastward or northeastward (the North Atlantic Current and the Azores Current) in CTRL (Fig. 4a, b), the sea-ice movement is thus turned to southwestward in WIND0.1 (Fig. 9d), resulting in significant expansion in sea-ice margin. It is worth noting that although the upper ocean in the mid and high latitudes becomes seriously colder $\left(6{ }^{\circ} \mathrm{C}\right.$ cooling generally), sea ice still has to melt as long as the ocean temperature is above the freezing point of seawater. The sea-ice melting rate is about $0.2-0.3 \mathrm{psu} /$ month in WIND0.1 (Fig. 9d), in good agreement with the magnitude of salinity increase by WDC advection (Fig. 5b).

In the mid-high latitudes between $40-60^{\circ} \mathrm{N}$, sea-ice melting determines ocean surface freshening (Figs. 9d, e, f). We can see strong melting occurs only when both the THC and WDC are shut down (Fig. 9d). The sea-ice melting related to either WDC or THC shutdown is relatively weak (Fig. 9e, f). It has been shown in Fig. 5b that the WDC advection change has salinification effect on the upper ocean between $40-60^{\circ} \mathrm{N}$. Therefore, it is the sea-ice melting that plays a vital role in AMOC change in WIND0.1. Results in the next subsection further suggest a positive feedback between sea-ice melting and AMOC weakening. However, the triggering mechanism for AMOC change during the first few years cannot be attributed to sea-ice change.

\subsection{Triggering mechanism and positive feedback during transient period}

To examine the transient AMOC change in WIND0.1, six ensemble experiments are performed. Each run is integrated for 100 years, starting from six different times of CTRL. The wind stress forcing in the ensemble runs is the same as that in WIND0.1. Figure 10 shows the ensemble mean changes in the AMOC, MLD, salinity, temperature, and the terms in the salinity equation. All variables except the AMOC index are averaged within the box of $40-55^{\circ} \mathrm{N}$, $30-60^{\circ} \mathrm{W}$. All terms except the source term in the salinity equation are calculated online. The salinity equation with these terms is simply written as,

$\frac{\partial S}{\partial t}=-\left(u \frac{\partial S}{\partial x}+v \frac{\partial S}{\partial y}+w \frac{\partial S}{\partial z}\right)+A_{H} \nabla^{2} S+\frac{\partial}{\partial z} \kappa \frac{\partial S}{\partial z}+Q_{S}$,

$Q_{S}=V S F_{E M P}+V S F_{\text {ice }}+$ River $_{\text {runoff }}$,

$V S F_{\text {ice }}=$ Melt_F$+I o f f_{-} F+$ Salt_F,

where the terms on the right hand side of Eq. (2) are salinity advections, horizontal salinity diffusion, vertical salinity diffusion, and the source term, respectively. The source term $Q_{S}$ in Eq. (3) consists of virtual salt fluxes due to evaporation and precipitation $\left(V S F_{E M P}\right)$, sea-ice formation $\left(V S F_{i c e}\right)$ and river runoff. Sea-ice formation in Eq. (4) includes sea-ice generation or melting in the high latitudes $\left(M e l t_{-} F\right)$, the continental ice influx (Ioff_F) due to landmodel snow capping and the salt flux (Salt_F) due to the salinity gradient between ice and water. Usually, Ioff_F and Salt_F are 2 to 3 orders smaller than Melt_F, so $V S F_{\text {ice }}$ is practically determined by sea-ice formation or melting only. Figure 10 shows the differences of the terms between WIND0.1 and CTRL.

The AMOC weakening in WIND0.1 during the first few years is caused by the weakening of vertical salinity diffusion and convection in the region of deep-water formation (solid grey curve in Fig. 10b). At least in the first 20 years right after the sudden wind stress reduction, vertical salinity diffusion (including convection) is the dominant factor 
(a)

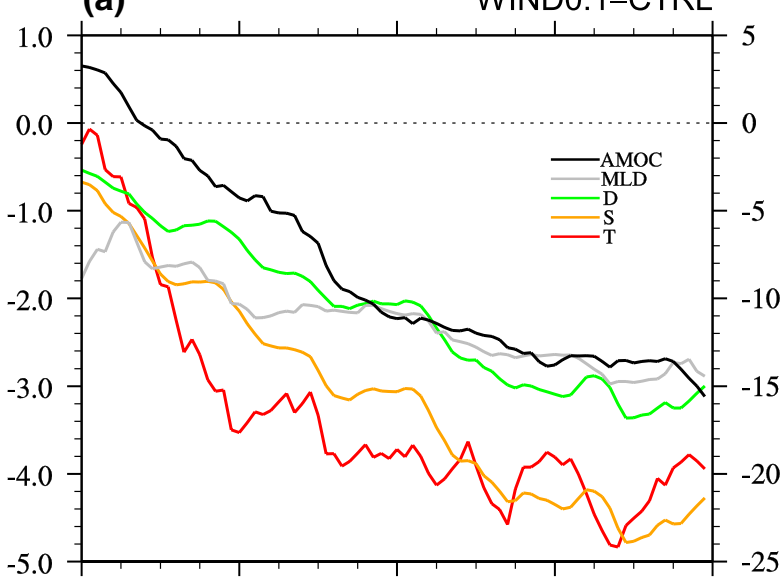

(b)

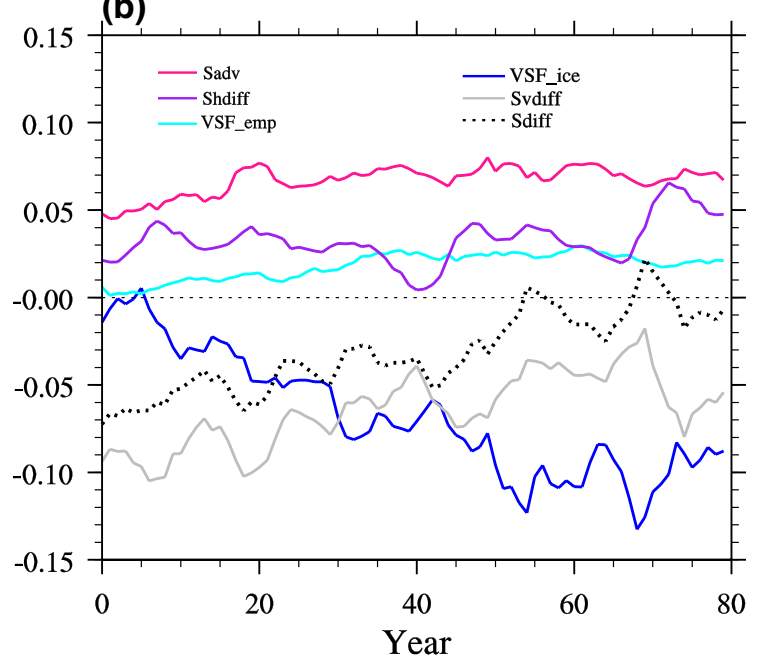

Fig. 10 Ensemble mean changes in WIND0.1 during the first 80 years. In a, the black curve is for the AMOC index; the green for potential density $\left(\mathrm{kg} / \mathrm{m}^{3}\right)$; the orange for salinity (psu); the red for potential temperature $\left({ }^{\circ} \mathrm{C}\right.$ ); and the grey for MLD (unit in $30 \mathrm{~m}$ ). The right $y$-axis is for the AMOC index, and the left, for the other variables. In $\mathbf{b}$, the terms contributing to salinity change are diagnosed (psu/month). The red curve is for three-dimensional advection; the blue for sea-ice melting; the cyan for virtual salt flux due to EMP; the purple for horizontal diffusion; and the grey for vertical diffusion. The black dashed curve is for the sum of horizontal and vertical diffusion terms. All variables, except for the AMOC index, in a are averaged over the box of $40-55^{\circ} \mathrm{N}, 30-60^{\circ} \mathrm{W}$ and $0-30 \mathrm{~m}$

for the AMOC change. (Note that vertical diffusion also includes convection effect. The coupled model used in this study is incapable of resolving convection effect explicitly. Instead, it is parameterized as part of vertical diffusion.) In fact, vertical salinity diffusion (including convection) is the only factor in the first few years, which triggers the AMOC weakening. Thereafter, sea-ice melting starts to take effect (solid blue curve in Fig. 10b). The effect of vertical diffusion on the AMOC diminishes with time, accompanied by enhanced sea-ice melting effect. The latter (a) S (psu)

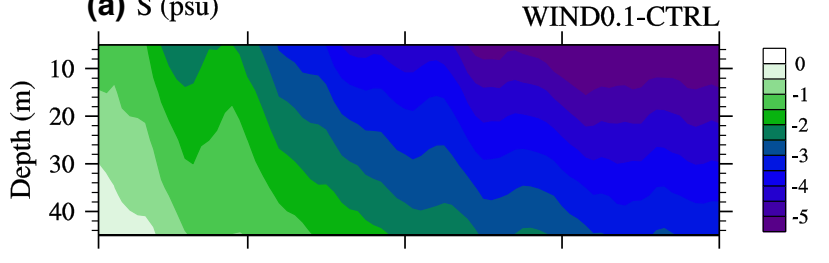

(b) $\mathrm{dS} / \mathrm{dz}\left(\mathrm{x} 10^{-2} \mathrm{psu} / \mathrm{m}\right)$

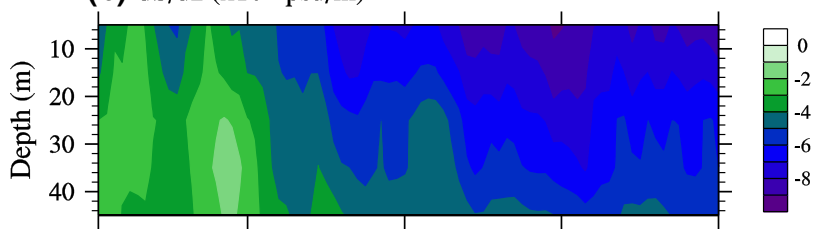

(c) $\mathrm{d}^{2} \mathrm{~S} / \mathrm{dz}^{2}\left(\times 10^{-4} \mathrm{psu} / \mathrm{m}^{2}\right)$

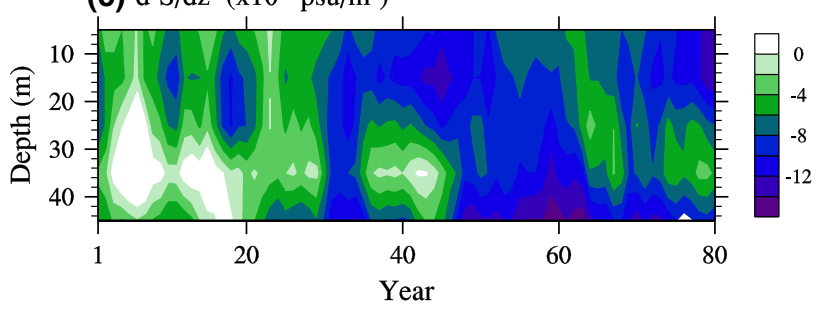

Fig. 11 Temporal evolutions of changes in a salinity (psu), b vertical salinity gradient $\left(\mathrm{dS} / \mathrm{dz} ; 10^{-2} \mathrm{psu} / \mathrm{m}\right)$ and $\mathbf{c}$ vertical salinity diffusion $\left(\mathrm{d}^{2} \mathrm{~S} / \mathrm{d}^{2} \mathrm{z} ; 10^{-4} \mathrm{psu} / \mathrm{m}^{2}\right)$ during the first 80 years in WIND0.1. In $\mathbf{b}$, negative value shows enhanced vertical salinity gradient. All variables are averaged over the box of $46-48^{\circ} \mathrm{W}$ and $50-55^{\circ} \mathrm{N}$

becomes dominant in 30 years. The weakened convection in WIND0.1 is also implied by MLD change, which is shoaled instantly by $20-30 \mathrm{~m}$ in the first year (grey curve in Fig. 10a). The other factors, including horizontal salinity diffusion, horizontal and vertical salinity advections, and the net surface freshwater flux due to EMP, all have salinification effects on upper-ocean salinity, which help to enhance the AMOC in WIND0.1.

The change in salinity advection in the deep-water formation region tends to increase salinity (red solid curve in Fig. 10b, also see Fig. 5b). (The total salinity advection change includes change due to perturbation circulation and change due to salinity anomaly, but the latter can be neglected.) This is counter-intuitive since we usually think saline water is transported from the lower latitudes, and once this saline water transport is shut down, the salinity in the high latitudes should be reduced. This occurs because the WDC advection dominates the salinity tendency between 30 and $60^{\circ} \mathrm{N}$ (Fig. $5 \mathrm{~b}$ ), where the winddriven subpolar gyre tends to transport high-latitude fresher water southward along the western boundary. It is true that there is also saline water advection from the tropics, but it is carried by the THC (Fig. 5a) and is much weaker than the WDC advection of fresher water. In general, lack of 
WDC advection increases the upper-ocean salinity in the deep-water formation region.

The surface freshwater flux due to EMP change also has salinification effect on ocean salinity (cyan curve in Fig. 10b). Lower SST and weakened wind stress reduce atmospheric moisture content, the mid-high latitude convection and thus the precipitation, more seriously than they reduce surface evaporation (figure not shown). Actually, except for the deep tropics, the global precipitation is diminished significantly in association with lower global temperature. This is particularly clear over the colder extratropics (not shown), where atmospheric ascending movement and moisture supply from the ocean and lower latitudes are weakened substantially, accompanied by the weakened poleward ocean heat transport and atmospheric moisture transport (Yang and Dai 2014).

The transient change of vertical salinity diffusion in the deep-water formation region in WIND0.1 is further examined using Fig. 11. Previous studies (e.g., Oka et al. 2001) suggested that vertical diffusion in the high latitudes has a stabilizing effect on the THC. Weaker vertical diffusion helps to re-establish the halocline in the upper ocean, hindering the vertical exchange of salt flux and thus destabilizing the THC. Reducing the surface wind forcing can immediately weaken the convection and vertical stirring of the ocean as well as the Ekman pumping in the subpolar gyre, enhancing vertical salinity stratification. This process is clearly shown in Fig. 11. With the weakened (negative) vertical diffusion (Fig. 11c), upper-ocean salinity gradient is enhanced (Fig. 11b), triggering freshening at the ocean surface, which penetrates downward rapidly with time (Fig. 11a).

The sea-ice change takes effect about 10 years after the wind shutdown. The positive feedback between surface salinity change and THC strength appears to be bridged by sea-ice dynamics in WIND0.1, instead of by northward salinity advection from the tropics. Figure 12 shows the temporal evolution of anomalous sea ice in WIND0.1. Different colors show sea-ice melting (formation) and margin at different stages. Sea-ice melting (formation) is enhanced with time towards lower (higher) latitudes, following seaice expansion closely. Initially, the anomalous sea-ice melting occurs mainly in the Labrador Sea (bright blue shading in Fig. 12), and then expands southward towards the region of Gulf Stream extension. Sea-ice margin roughly reaches equilibrium 60 years after the wind shutdown (light green curve in Fig. 12). By then, the AMOC in WIND0.1 is reduced by about $80 \%$.

The triggering mechanism and positive feedback described above are illustrated schematically in Fig. 13. When surface wind stress is reduced, the WDC is weakened immediately, resulting in a slight overshooting of the AMOC. At the same time, due to the weakening of vertical

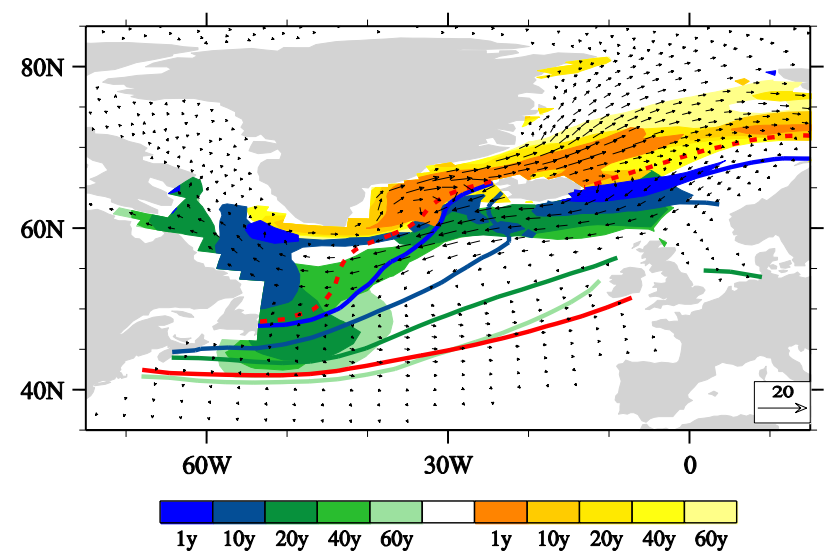

Fig. 12 Temporal evolutions of changes in sea-ice formation (color shading; psu/month) and sea-ice margin (color curves) during the first 60 years in WIND0.1. Mean sea-ice velocity difference between WIND0.1 and CTRL is superimposed. Same as Fig. 9, negative seaice formation means sea-ice melting. Different colors represent seaice formation and margin in different years. The dashed (solid) red curve represents equilibrium sea-ice margin in CTRL (WIND0.1). The color shadings represent sea-ice melting (formation) by more than $-0.1(+0.1) \mathrm{psu} / \mathrm{month}$ in corresponding years

salinity diffusion (and convection), upper-ocean salinity stratification is enhanced, hindering deep-water formation and triggering the weakening of the THC. Sea ice starts to expand southward and then melts, supplying fresh water to the surface ocean in the main deep-water formation region, which in turn reduces the THC further. The sea ice responds with more southward expansion and melting. This positive feedback will finally result in a completely shutdown of the AMOC.

\section{Summary and discussion}

The AMOC consists of the WDC and the THC. Using a fully coupled climate model, we quantified individual contributions of WDC and THC to the upper-ocean buoyancy through sensitivity experiments (Fig. 5). The WDC advection has freshening and cooling effects on the subtropical upper ocean, and salinification and warming effects on the subpolar upper ocean (Fig. 5b, e). On the contrary, the THC advection has freshening and cooling effects on the subpolar ocean and weak salinification and warming effects on the subtropical ocean. Our model sensitivity experiments show that the WDC advection appears to be more important than the THC advection in determining upper-ocean buoyancy in the Atlantic (Fig. 5).

Here, we would like to discuss the justification of splitting AMOC in this study. In theory, the THC and WDC are strongly related and cannot be separated (Lozier 2010); however, in practice, they can be roughly separated in 
Fig. 13 Schematic diagram showing the triggering mechanism for THC weakening and the positive feedback between sea ice and THC during the transient period in WIND0.1

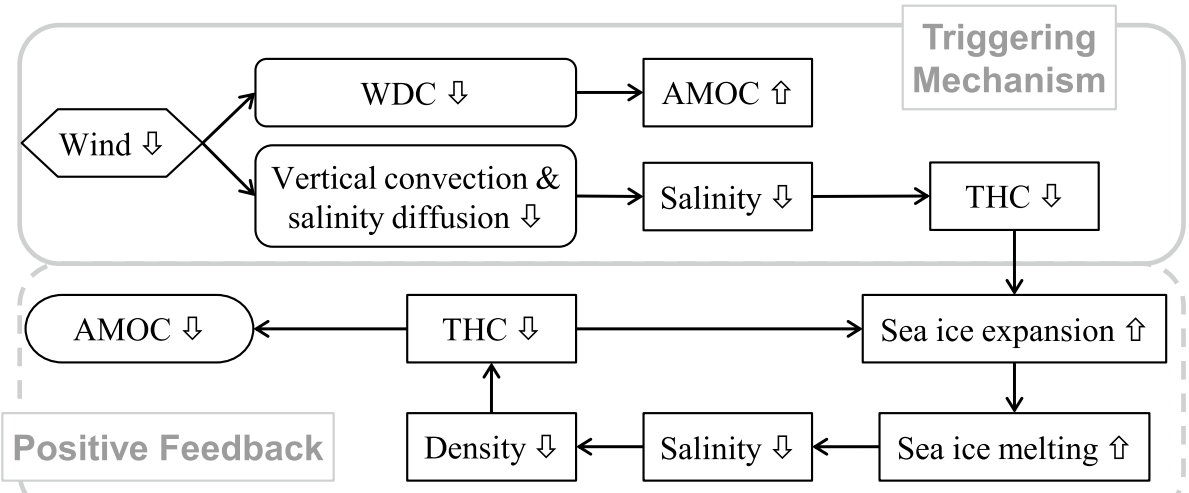

numerical models, as done in Timmermann and Goosse (2004) and the references therein. In fact, oceanographers used to split WDC and THC based on a more classical approach: the WDC is usually obtained as the zonal anomaly circulation and the THC is obtained from the zonal mean (e.g., Bryden and Imawaki 2001; Marti et al. 2010). This classical decomposition is simple and can provide a framework for describing responses of the ocean to different surface forcing factors. We have compared THC and WDC obtained from these two approaches. The WDC obtained from the classical approach (figure not shown) is similar to that from the sensitivity experiments (Fig. 4b) in terms of spatial pattern and magnitude. However, the horizontal pattern of the THC cannot be well identified based on the classical approach. The THC from the sensitivity experiments (Fig. 4a) shows more reasonable structure and is also similar to those in previous studies (e.g., Timmermann and Goosse 2004). This splitting is critical for this work to calculate horizontal advection terms of salinity and temperature by the THC. We suspect that it may even be a better way to decompose the Atlantic circulation through properly designed sensitivity experiments. Of course, the classical approach may be the only approach when dealing with observations.

With the help of sensitivity experiments, the effect of wind forcing on the AMOC was analyzed in detail. Similar to previous studies, the wind stress forcing was found to be crucial to the AMOC. Different from some studies (Schiller et al. 1997; Timmermann and Goosse 2004), we emphasize that the wind effect on the AMOC is accomplished via vertical diffusion, convection and sea-ice feedback. The vertical salinity diffusion (and convection) is responsible for triggering THC change in response to the sudden surface wind change. During the transient period of ocean change, a positive feedback between sea ice and THC strength is emerged as the dominant mechanism for the AMOC change. These processes are summarized in Fig. 13.

We wish to note that the sea-ice feedback mechanism proposed here does not contradict the classical Stommel advection feedback mechanism for the AMOC change. In different experiments, the major mechanism can be different. In our freshwater-hosing experiments, the THC changes while the WDC does not change. Therefore, the THC advection change dominates the salinity change in the region of NADW formation, and the Stommel advection positive feedback works very well, consistent with previous studies using different models (e.g., Swingedouw et al. 2007). In our wind-perturbation experiments, both the THC and the WDC change significantly. The effect of WDC advection on salinity is found to be opposite to and dominant over the effect of THC advection. The weakening of WDC advection is not the reason of the surface freshening. The sea-ice melting is found to be responsible here, and the sea-ice positive feedback results in a complete shutdown of the AMOC in the wind-perturbation experiments.

Wind forcing can also affect the AMOC indirectly by altering upwelling in the Southern Ocean. On the timescale discussed in this paper, this indirect effect cannot be identified. We believe that it is the local wind in the North Atlantic matters the most for the AMOC change on short timescales, since the northward salinity advection is not the main reason for the AMOC change in this study. Local wind affects local convection and diffusion, triggering AMOC change and then causing the chain reaction in ocean circulation and sea ice. Actually, we performed a series of local wind-perturbation experiments, in which only the wind forcing over the North Atlantic, the Pacific or the Southern Ocean was reduced by $90 \%$, respectively. The results from the Atlantic wind-perturbation experiment were similar to the global wind-perturbation experiment reported in this paper. Due to limited space, detailed analyses of these experiments will be presented in another paper.

The results from the extreme wind-perturbation experiments may not be comparable to any observed features. The role of sea ice in the AMOC change is surely exaggerated in this study. However, a better understanding of detailed seaice process can be fulfilled by assuming these unrealistic scenarios. For example, a meaningful question for the real world 
can be as follows: How does the low-frequency variability in wind stress affect the AMOC (directly or indirectly) via affecting sea ice? The AMOC change is determined by many processes, and which mechanism dominates may largely depend on timescale of the variability. Our results presented here suggest that the sea-ice feedback may emerge as an important factor in AMOC variability on decadal and longer timescales. We are currently working on a long, realistic control simulation using the high-resolution version of CESM1.0, to investigate the natural variability of see ice and AMOC.

The conclusions drawn in this study may be modeldependent and are subject to model limitations. For example, our model results show a relatively weak convection in the Labrador Sea, when compared to the convection in the GIN seas and observations. The cause may be related to model ocean's horizontal resolution. The ocean model used in this paper cannot fully resolve the convection in the Labrador Sea. We have examined the mean MLD in a high-resolution CESM control run. Strong convection occurs in both the Labrador Sea and GIN seas (figure not shown), consistent with observations and other model studies (Yeager and Danabasoglu 2014). Studies using different models will help to determine the robustness of this work.

Acknowledgments This research is jointly supported by the NSF of China (Nos. 91337106, 41376007, 41176002, and 40976007), and by the National Basic Research Program of China (No. 2012CB955200). All the experiments were performed on the supercomputer at the LaCOAS of Peking University.

Open Access This article is distributed under the terms of the Creative Commons Attribution 4.0 International License (http://creativecommons.org/licenses/by/4.0/), which permits unrestricted use, distribution, and reproduction in any medium, provided you give appropriate credit to the original author(s) and the source, provide a link to the Creative Commons license, and indicate if changes were made.

\section{References}

Arzel O, Colin De Verdière A, England MH (2009) The role of oceanic heat transport and wind stress forcing in abrupt millennialscale climate transitions. J Clim 23:2233-2256

Bentsen M, Drange H, Furevik T, Zhou T (2004) Simulated variability of the Atlantic meridional overturning circulation. Clim Dyn 22:701-720

Böning CW, Scheinert M, Dengg J, Biastoch A, Funk A (2006) Decadal variability of subpolar gyre transport and its reverberation in the North Atlantic overturning. Geophys Res Lett 33:0094-8276. doi:10.1029/2006GL026906

Brady EC, Otto-Bliesner BL (2010) The role of meltwater-induced subsurface ocean warming in regulating the Atlantic meridional overturning in glacial climate simulations. Clim Dyn. doi:10.1007/s00382-010-0925-9

Bryden HL, Imawaki S (2001) Ocean heat transport. In: Siedler G, Church JA, Gould J (eds) Ocean circulation and climate: observing and modelling the global ocean. Academic Press, San Diego, pp $445-474$
Chang P, Zhang R, Hazeleger W, Wen C, Wan X, Ji L, Haarsma RJ, Breugem W, Seidel H (2008) Oceanic link between abrupt changes in the North Atlantic Ocean and the African monsoon. Nat Geosci 1:444-448

Danabasoglu G, Bates SC, Briegleb BP, Jayne SR, Jochum M, Large WG, Peacock S, Yeager SG (2012) The CCSM4 ocean component. J Clim 25:1361-1389

Delworth TL, Mann ME (2000) Observed and simulated multidecadal variability in the Northern Hemisphere. Clim Dyn 16:661-676

Delworth TL, Zeng F (2008) Simulated impact of altered Southern Hemisphere winds on the Atlantic meridional overturning circulation. Geophys Res Lett 35:L20708. doi:10.1029/200 8 GL035166

Delworth TL, Manabe S, Stouffer RJ (1993) Interdecadal variations of the thermohaline circulation in a coupled ocean-atmosphere model. J Clim 6:1993-2011

Delworth TL, Manabe S, Stouffer RJ (1997) Multidecadal climate variability in the Greenland Sea and surrounding regions: a coupled model simulation. Geophys Res Lett 24:257-260. doi:10.1029/96GL03927

Dima M, Lohmann G (2007) A hemispheric mechanism for the Atlantic Multidecadal Oscillation. J Clim 20:2706-2719

Döös K, Webb D (1994) The Deacon Cell and the other meridional cells of the southern ocean. J Phys Oceanogr 24:429-442

Drinkwater KF, Miles M, Medhaug I, Otterå OH, Kristiansen T, Sundby S, Gao Y (2014) The Atlantic multidecadal oscillation: its manifestations and impacts with special emphasis on the Atlantic region north of $60^{\circ} \mathrm{N}$. J Mar Syst 133:117-130

Eden C, Willebrand J (2001) Mechanism of interannual to decadal variability of the North Atlantic circulation. J Clim 14:2266-2280

Elliot M, Labeyrie L, Duplessy J (2002) Changes in North Atlantic deep-water formation associated with the Dansgaard-Oeschger temperature oscillations (60-10 ka). Quat Sci Rev 21:1153-1165

Goldsbrough GR (1933) Ocean currents produced by evaporation and precipitation. Proc R Soc Lond Ser A 141:241-248

Gregory JM, Tailleux R (2011) Kinetic energy analysis of the response of the Atlantic meridional overturning circulation to $\mathrm{CO}_{2}$-forced climate change. Clim Dyn 37:893-914

Häkkinen S, Rhines PB (2004) Decline of subpolar north Atlantic circulation during the 1990s. Science 304:555-559

Hazeleger W, Drijfhout S (2006) Subtropical cells and meridional overturning circulation pathways in the tropical Atlantic. J Geophys Res 111:C03013. doi:10.1029/2005JC002942

Holland MM, Bitz CM, Eby M, Weaver AJ (2001) The role of iceocean interactions in the variability of the North Atlantic thermohaline circulation. J Clim 14:656-675

Huang B, Xue Y, Kumar A, Behringer DW (2012) AMOC variations in 1979-2008 simulated by NCEP operational ocean data assimilation system. Clim Dyn 38:513-525

Huang W, Wang B, Li L, Dong L, Lin P, Yu Y, Zhou T, Liu L, Xu S, Xia K (2014) Variability of atlantic meridional overturning circulation in FGOALS-g2. Adv Atmos Sci 31:95-109

Hunke EC, Lipscomb WH (2008) CICE: The Los Alamos Sea Ice Model, documentation and software user's manual, version 4.0. Tech. Rep. LA-CC-06-012, Los Alamos National Laboratory

Jungclaus JH, Haak H, Latif M, Mikolajewicz U (2005) Arctic-North Atlantic interactions and multidecadal variability of the meridional overturning circulation. J Clim 18:4013-4031

Killworth PD (1983) Deep convection in the world ocean. Rev Geophys $21: 1-26$

Knight JR, Allan RJ, Folland CK, Vellinga M, Mann ME (2005) A signature of persistent natural thermohaline circulation cycles in observed climate. Geophys Res Lett 32:L20708. doi:10.1029/20 05GL024233

Kuhlbrodt T, Griesel A, Montoya M, Levermann A, Hofmann M, Rahmstorf S (2007) On the driving processes of the Atlantic 
meridional overturning circulation. Rev Geophys 45:RG2001. doi: 10.1029/2004RG000166

Large WG, Danabasoglu G, Doney SC, McWilliams JC (1997) Sensitivity to surface forcing and boundary layer mixing in a global ocean model: annual-mean climatology. J Phys Oceanogr 27:2418-2447

Latif M, Roeckner E, Botzet M, Esch M, Haak H, Hagemann S, Jungclaus J, Legutke S, Marsland S, Mikolajewicz U (2004) Reconstructing, monitoring, and predicting multidecadal-scale changes in the North Atlantic thermohaline circulation with sea surface temperature. J Clim 17:1605-1614

Lawrence DM, Oleson KW, Flanner MG, Fletcher CG, Lawrence PJ, Levis S, Swenson SC, Bonan GB (2012) The CCSM4 land simulation, 1850-2005: assessment of surface climate and new capabilities. J Clim 25:2240-2260

Lozier MS (2010) Deconstructing the conveyor belt. Science 328:1507-1511

Manabe S, Stouffer RJ (1999) Are two modes of thermohaline circulation stable? Tellus A 51:400-411

Manabe S, Strouffer RJ (1995) Simulation of abrupt climate change induced by freshwater input to the North Atlantic Ocean. Nature 378:165-167

Marotzke J (1997) Boundary mixing and the dynamics of threedimensional thermohaline circulations. J Phys Oceanogr 27:1713-1728

Marshall J, Kushnir Y, Battisti D, Chang P, Czaja A, Dickson R, Hurrell J, McCARTNEY M, Saravanan R, Visbeck M (2001) North Atlantic climate variability: phenomena, impacts and mechanisms. Int J Climatol 21:1863-1898

Marti O et al (2010) Key features of the IPSL ocean atmosphere model and its sensitivity to atmospheric resolution. Clim Dyn 34:1-26. doi:10.1007/s00382-009-0640-6

McManus JF, Francois R, Gherardi J, Keigwin LD, Brown-Leger $S$ (2004) Collapse and rapid resumption of Atlantic meridional circulation linked to deglacial climate changes. Nature 428:834-837

Meehl GA, Washington WM, Arblaster JM, Hu A, Teng H, Kay JE, Gettelman A, Lawrence DM, Sanderson BM, Strand WG (2013) Climate change projections in CESM1 (CAM5) compared to CCSM4. J Clim 26:6287-6308

Mignot J, Ganopolski A, Levermann A (2007) Atlantic subsurface temperatures: response to a shutdown of the overturning circulation and consequences for its recovery. J Clim 20:4884-4898

Neale RB (2010) Description of the NCAR Community Atmosphere Model 726 (CAM5. 0), Tech. Rep. NCAR/TN-486+ STR, National Center for Atmospheric Research, Boulder, CO, USA

Neale RB, Richter J, Park S, Lauritzen PH, Vavrus SJ, Rasch PJ, Zhang M (2013) The mean climate of the Community Atmosphere Model (CAM4) in forced SST and fully coupled experiments. J Clim 26:5150-5168

Nilsson J, Broström G, Walin G (2003) The thermohaline circulation and vertical mixing: does weaker density stratification give stronger overturning? J Phys Oceanogr 33:2781-2795

Oka A, Hasumi H, Suginohara N (2001) Stabilization of thermohaline circulation by wind-driven and vertical diffusive salt transport. Clim Dyn 18:71-83

Oppo DW, Lehman SJ (1995) Suborbital timescale variability of North Atlantic deep water during the past 200,000 years. Paleoceanography 10:901-910
Schiller A, Mikolajewicz U, Voss R (1997) The stability of the North Atlantic thermohaline circulation in a coupled ocean-atmosphere general circulation model. Clim Dyn 13:325-347

Smith RD et al (2010) The Parallel Ocean Program (POP) reference manual. Tech. Rep. LAUR-10-01853, Los Alamos National Laboratory

Stocker TF, Wright DG (1991) Rapid transitions of the ocean's deep circulation induced by changes in surface water fluxes. Nature 351:729-732

Stouffer RJ, Seidov D, Haupt BJ (2007) Climate response to external sources of freshwater: North Atlantic versus the Southern Ocean. J Clim 20:436-448

Swingedouw D, Braconnot P, Delecluse P, Guilyardi E, Marti O (2007) The impact of global freshwater forcing on the thermohaline circulation: adjustment of North Atlantic convection sites in a CGCM. Clim Dyn 28:291-305. doi:10.1007/ s00382-006-0171-3

Swingedouw D, Fichefet T, Goosse H, Loutre MF (2009) Impact of transient freshwater releases in the Southern Ocean on the AMOC and climate. Clim Dyn 33:365-381. doi:10.1007/ s00382-008-0496-1

Timmermann A, Goosse H (2004) Is the wind stress forcing essential for the meridional overturning circulation? Geophys Res Lett 31:L04303. doi:10.1029/2003GL018777

Toggweiler JR, Samuels B (1995) Effect of Drake passage on the global thermohaline circulation. Deep Sea Res Part I Oceanogr Res Pap 42:477-500

Toggweiler JR, Samuels B (1998) On the ocean's large-scale circulation near the limit of no vertical mixing. J Phys Oceanogr 28:1832-1852

Vidal L, Labeyrie L, Cortijo E, Arnold M, Duplessy JC, Michel E, Becque S, Van Weering T (1997) Evidence for changes in the North Atlantic deep water linked to meltwater surges during the Heinrich events. Earth Planet Sci Lett 146:13-27

Weaver AJ, Marotzke J, Cummins PF, Sarachik ES (1993) Stability and variability of the thermohaline circulation. J Phys Oceanogr 23:39-60

Welander P (1986) Thermohaline effects in the ocean circulation and related simple models. Large-scale transport processes in oceans and atmosphere. Springer, Berlin, pp 163-200

Wunsch C (2000) Moon, tides and climate. Nature 405:743-744

Wunsch C, Ferrari R (2004) Vertical mixing, energy, and the general circulation of the oceans. Annu Rev Fluid Mech 36:281-314

Yang HJ, Dai HJ (2014) Effect of wind forcing on the meridional heat transport in a coupled climate model: equilibrium response. Clim Dyn. doi:10.1007/s00382-014-2393-0

Yang HJ, Li Q, Wang K, Sun Y, Sun DX (2014) Decomposing the meridional heat transport in the climate system. Clim Dyn. doi:10.1007/s00382-014-2380-5

Yeager S, Danabasoglu G (2014) The origins of late-twentieth-century variations in the large-scale North Atlantic circulation. J Clim 27:3222-3247

Zhang R, Vallis GK (2006) Impact of great salinity anomalies on the low-frequency variability of the North Atlantic climate. J Clim 19:470-482 